\title{
Induced Demand and Rebound Effects in Road Transport
}

\author{
Kent M. Hymel*, Kenneth A. Small**, and Kurt Van Dender*** \\ University of California, Irvine
}

February 5, 2010

* Corresponding author: Dept. of Economics, University of California, Irvine, CA 92697-5100, USA; khymel@uci.edu; (617) 494-2479.

** Dept. of Economics, University of California, Irvine, CA 92697-5100, USA

*** Joint Transport Research Centre of the International Transport Forum and the OECD, Paris, France

Keywords: vehicle-miles traveled, congestion, rebound effect, induced demand

JEL codes: H54, L91, Q49, R41,

\begin{abstract}
This paper analyzes aggregate personal motor-vehicle travel within a simultaneous model of aggregate vehicle travel, fleet size, fuel efficiency, and congestion formation. We measure the impacts of driving costs on congestion, and two other well-known feedback effects affecting motor-vehicle travel: its responses to aggregate road capacity ("induced demand") and to driving costs including those caused by fuel-economy improvements ("rebound effect"). We measure these effects using cross-sectional time series data at the level of US states for 1966 through 2004. Results show that congestion affects the demand for driving negatively, as expected, and more strongly when incomes are higher. We decompose induced demand into effects from increasing overall accessibility of destinations and those from increasing urban capacity, finding the two elasticities close in magnitude and totaling about 0.16 , somewhat smaller than most previous estimates. We confirm previous findings that the magnitude of the rebound effect decreases with income and increases with fuel cost, and find also that it increases with the level of congestion.
\end{abstract}




\section{Induced Demand and Rebound Effects in Road Transport}

\section{Introduction}

Transportation policies are accompanied by several feedback effects. One of them is the "induced demand effect” for vehicle travel, whereby increases in highway capacity attract new traffic (Downs, 1962; Goodwin, 1996), possibly working against the intent of the capacity increase or at least causing new facilities to be unexpectedly crowded. Another effect is the “rebound effect” (Greening, Greene, and Difiglio, 2000), by which policies or technical improvements that raise fuel efficiency also decrease the per-mile fuel cost of driving and hence cause an increase in vehicle usage. Because of the rebound effect, fuel efficiency improvements save less fuel than in the case of unchanged travel demand.

Both feedback effects are instances of more general phenomena involving offsetting behavior. For example, making cars safer might increase their use for the same reason as fuelefficiency improvements, if people regard accident costs as part of the cost of driving. As for induced demand, any policy that reduces congestion without otherwise making driving more expensive, for example diverting some commuters to transit, will tend to attract new traffic that at least partially offsets the policy's effect on congestion. Because of the rebound effect as just explained, fuel-efficiency improvements are one such policy, except working in the opposite direction. If fuel-efficiency improvements increase travel demand at locations and times where congestion is present, they will tend to worsen congestion, which will itself tend to deter travel by exactly the reverse of the mechanism that produces induced demand. Both feedback effects interact, and more specifically the rebound effect will be dampened by congestion.

This paper simultaneously measures the induced-demand and rebound effects while taking into account endogenous urban congestion. In order to accomplish this, we directly model the simultaneous interaction between vehicle miles traveled (VMT) and congestion. We distinguish two sources of induced demand: that occurring in undeveloped areas when new locations are made more accessible, and that occurring in urban areas because increased capacity tends to reduce congestion, and this attracts increased traffic. Our modeling of congestion also provides a more accurate estimate of the rebound effect than earlier studies, and it enables us to estimate the congestion impacts of fuel-efficiency policies — which here we call the "congestion effect”. 
Our model is an extension of that by Small and Van Dender (2007). They model the simultaneous determination of vehicle miles traveled, vehicle stock, and fuel efficiency; we add congestion. We also extend their 1966-2001 panel data set, aggregated at the level of US states (plus District of Columbia), to 2004. We estimate the model using three-stage least squares (3SLS) in order to account for the endogeneity of explanatory variables. Our results contain both short-run and long-run estimates because we allow for lagged effects within annual data. For VMT, the behavioral responses underlying short-run effects could include changes in travel mode, discretionary trips, destinations, or the combining of several trips into a single chain. Long-run responses might include changes in the vehicle stock, job or residential relocations, and changes in land use. Except for vehicle stock, we do not model these other decisions explicitly. The model enables one to calculate price elasticities of fuel consumption, and to see how they are determined by separate pathways involving changes in vehicle fleet size, vehicle usage, and average fuel efficiency.

The results help assess policy. For example, Portney et al. (2003) argue that the US Corporate Average Fuel Economy (CAFE) standards increase urban congestion enough that the extra costs of congestion seriously erode or even reverse the benefits of less fuel consumption. However, newer evidence suggests that the rebound effect in the US today is considerably lower than in the past - mainly due to rising real incomes - and is therefore lower than previous estimates in the literature (Small and Van Dender, 2007). We confirm that result here while accounting for the role of congestion, which means it becomes less likely that increased costs of congestion outweigh the benefits of reduced fuel consumption.

We measure the two distinct sources of "induced demand" mentioned earlier through two different measures of road stock. The first source (accessibility) is measured as a direct response of travel to changes in total road length. The second is measured as an indirect response to changes in urban road capacity operating via endogenous congestion. Incorporating both of these sources, our estimate of the elasticity of state VMT with respect to total road length is 0.037 in the short run and 0.186 in the long run, calculated at the average values of variables in our sample in the year 2004. About 60 percent of this induced demand works through the path of increased accessibility and 40 percent through decreased congestion. (If only non-metropolitan rural road lengths or only urban road widths are increased, then just one of these pathways is applicable.) Because our geographical unit is a U.S. state (or the District of Columbia), our 
measures net out some "induced travel” that is measured in studies of smaller areas or of individual corridors, namely, the travel that is diverted from nearby areas to ones whose accessibility or capacity is increased.

Our results on congestion permit us to examine how congestion impacts the rebound effect. We estimate the "congestion effect" - i.e. the elasticity of total congestion delay with respect to an exogenous increase in fuel efficiency — to be 0.012 in the short run and 0.060 in the long run, again in year 2004. Using current estimates of congestion costs from Schrank and Lomax (2005), this result implies that increasing the average fleet fuel efficiency by one mile per gallon would raise delay caused by congestion by a modest 1.1 minutes per adult per year in the long run. This increased congestion modifies the overall rebound effect by curtailing some of the incentive for travel, but we find that modification to be modest, changing the short-run rebound effect by a negligible amount and reducing the long-run rebound effect (as measured for year 2004) from 0.135 to 0.131 .

The paper is structured as follows. Section 2 reviews literature on induced demand for travel and the rebound effect. Section 3 describes our theoretical model. Section 4 presents the econometric model and data, while Section 5 describes estimation results. Section 6 concludes.

\section{Literature review}

While a considerable amount of work has been done on induced demand and on the rebound effect, we know of no studies that jointly model both effects and their interdependence. For this reason, we review separately studies on induced demand and on the rebound effect.

\subsection{Induced demand for travel}

Transportation researchers have long recognized that any change in the transportation system that reduces congestion will, in the absence of some offsetting deterrent, cause travel on the congested facility to increase. This is in line with the common observation that the quantity demanded of a good increases as its price declines. Downs (1962), Smeed (1968), and Thomson (1977) suggest that such "induced demand" is so strong a phenomenon as to almost completely offset the congestion-reducing effect of a capacity improvement. For example, Smeed states that in British cities, “the amount of traffic adjusts itself to a barely tolerable speed” (p. 41) and he estimates that "if it were not for the inhibiting effects of congestion, we might well have 4 to 5 
times as much traffic in Central London as we have now" (p. 58). Holden (1989) provides more formal modeling of the phenomenon. Empirically, a report by the Standing Advisory Committee on Trunk Road Assessment (SACTRA, 1994) caused a major rethinking of road-expansion policies in the UK by demonstrating that traffic on a corridor responds significantly to road capacity. This and other evidence is reviewed by Goodwin (1996), who suggests from a broadbrush analysis of elasticities of VMT with respect to travel time that the induced-demand effect should be about 0.10 in the short run and 0.20 in the long run. ${ }^{1}$

A number of more recent studies have applied econometric techniques to a variety of data sources to determine the size of the induced demand effect. Hanson and Huang (1997) consider lane-mile additions to the California system of state highways, obtaining an elasticity of VMT with respect to lane miles of 0.6-0.9. Fulton et al. (2000) examine county-level data from selected mid-Atlantic areas in the US, while Noland (2001) uses a panel data set of US states to examine induced demand, modeling VMT as a function of lane-miles. Fulton et al. find best estimates of the elasticity of VMT with respect to lane miles to be $0.2-0.6$. Noland finds similar values for short-run elasticities of travel on particular classes of highways, but smaller values for overall travel: using his best-performing estimate that distinguishes between short- and long-run effects, one obtains short- and long-run elasticities of VMT with respect to lane miles of 0.13 and 0.41, respectively. ${ }^{2}$ Cervero and Hansen (2002) use a cross-sectional time series of 34 urban counties in California over 22 years to estimate a simultaneous-equations model of VMT and lane-miles. They argue that past studies have been plagued by simultaneity bias and propose a set of instrumental variables to eliminate it. Using these tools, they estimate the short- and long-run elasticities of VMT with respect to lane-miles to be 0.6 and 0.8 .

Cervero (2003) estimates a more elaborate model that explicitly accounts for congestion in the short run and for development activity in the long run. He examines 24 California freeway projects over a 15-year period and obtains much smaller net induced-travel elasticities with respect to lane miles: 0.10 in the short run and 0.39 in the long run. These estimates are very close to those of Noland (2001) just cited. Both are likely to somewhat overstate the induced demand over a large area such as an entire state: Cervero’s because, as he notes, his estimates

\footnotetext{
${ }^{1}$ This is based on Goodwin's text on p. 41, which appears to be referring to the response to a doubling of capacity.

${ }^{2}$ Noland (2001), Table 7, last column. The long-run elasticity is $0.128 /(1-0.690)=0.413$, where 0.690 is the coefficient of the one-year lagged value of the independent variable.
} 
include some travel that is diverted from other nearby corridors, and Noland's because his estimates do not account for the reverse causality whereby road building responds to actual or anticipated traffic.

We conclude that prior literature best supports short-run elasticities of vehicle miles traveled with respect to total urban and rural lane-miles to be on the order of 0.1 and long-run elasticities on the order of 0.4. These appear to be conservative lower bounds on the elasticities found in the literature (which, as just indicated, may tend to overestimate the effect), with the exception of one study that finds essentially zero elasticity using vehicle trips rather than vehicle miles as its dependent variable (Mokhtarian et al., 2002).

\subsection{The rebound effect}

Prior research has measured the rebound effect for passenger transport using a variety of data sources and statistical techniques. Most but not all estimates lie within a range of 10 to 30 percent (expressing the elasticity as an absolute value and as a percentage instead of a fraction). We refer to Greening, Greene, and Difiglio (2000) and Small and Van Dender (2007) for reviews. Here we just highlight a few key contributions.

The great majority of estimates are based on one of three types of data. The first and probably least satisfactory is a single time series, either of an entire nation or of a single state within the U.S. Examples are Greene (1992) and Jones (1993). These studies have difficulty distinguishing between autocorrelation and lagged effects, and of course suffer from a small number of data points.

Second, some studies have instead used state-level panel data, most often from the US Federal Highway Administration (FHWA). Haughton and Sarkar (1996), using such data from 1970-1991, estimate the rebound effect to be $16 \%$ in the short run and $22 \%$ in the long run. They account for endogenous regressors, autocorrelation, and lagged effects. Small and Van Dender (2007) use similar data but for a longer time period, 1966-2001, estimating three equations simultaneously explaining VMT, vehicle stock, and fuel efficiency. They estimate the rebound effect to be $4.5 \%$ in the short run and $22.2 \%$ in the long-run on average, and find evidence that it has declined substantially over time due mainly to rising per-capita incomes.

A third type of data is from individual households. Mannering (1986), using a US household survey, finds that how one controls for endogenous variables in a vehicle utilization 
equation strongly influences the estimated rebound effect. He estimates the short- and long-run rebound effects (constrained to be identical) to be 13-26\%. Goldberg (1998) estimates a system of equations using data from the Consumer Expenditure Survey for years 1984-1990. In a specification accounting for the simultaneity of the two equations, she cannot reject the hypothesis of a rebound effect of zero. Greene, Kahn and Gibson (1999) estimate the rebound effect to be $23 \%$ on average using a simultaneous-equation model of individual household decisions.

The studies based on individual households in a single cross-section suffer from a limited range for fuel prices, a key variable for understanding the rebound effect. This disadvantage is partly overcome by Dargay (2007), who observes repeated cross sections of different individuals in the UK. She estimates short- and long-run rebound effects of $10 \%$ and $14 \%$, respectively, but suggests that this long-run value may be an underestimate.

Two recent reviews - Goodwin, Dargay, and Hanly (2004) and Graham and Glaister (2004) - provide systematic statistical analyses of various studies. Estimated short- and long-run rebound effects (based on fuel-price elasticities) average about 12 percent and 30 percent, respectively.

This short overview highlights the importance of model specification. How one deals with dynamics — by including lagged effects, autoregressive errors, both, or neither — can have a major impact. In addition, results of US studies seem to be sensitive to how they account for the influence of the US Corporate Average Fuel Efficiency (CAFE) standards, which went into effect in 1978.

\section{Theoretical framework}

We motivate our empirical specification with a model that simultaneously determines four variables: aggregate vehicle miles traveled, vehicle stock, fuel efficiency, and traffic congestion. Our simultaneous model formalizes the key relationships, both direct and indirect, among these four variables. We use these relationships to derive expressions for the rebound effect, the induced demand effect, the congestion effect (i.e., the elasticity of traffic congestion with respect to fuel efficiency), and other elasticities.

First, we assume that VMT, denoted here by $M$, is a function of the vehicle stock $V$, the

per-mile fuel cost of driving $P_{M}$, traffic congestion $C$, accessibility-related road capital stock $K 1$, 
and exogenous factors $X_{M}$. Note that $P_{M}$ (the fuel cost of driving a mile, equal to the price of fuel $P_{F}$ divided by fuel efficiency $E$ ) is endogenous. We assume that a state's vehicle stock is a function of VMT, the price of a new vehicle $P_{V}$, the per-mile cost of driving, and other factors $X_{V}$. Consumers and manufacturers jointly determine vehicle fuel efficiency $E$, which we assume is a function of VMT, the price of fuel $P_{F}$, regulations $R_{E}$, and other factors $X_{E} \cdot{ }^{3}$ Finally, traffic congestion is a function of VMT, urban road capacity K2 (non-urban road capacity is assumed to be abundant), and other exogenous factors $X_{C}$. Thus:

$$
\begin{aligned}
M & =M\left(V, P_{M}, C, K 1, X_{M}\right) \\
V & =V\left(M, P_{V}, P_{M}, X_{V}\right) \\
E & =E\left(M, P_{F}, R_{E}, X_{E}\right) \\
C & =C\left(M, K 2, X_{C}\right) .
\end{aligned}
$$

This model is an extension of that by Small and Van Dender (2007). In their model, the effect of congestion is proxied crudely by including road-miles per adult as one of the variables in $X_{M}$. Here we fully incorporate congestion into the structural system and construct a more direct measure of it, as explained in section 4.3. We also specify two different measures of road capital stock operating through two different pathways.

\subsection{Partially-reduced-form elasticities}

It is convenient to solve the structural equation in two steps, first eliminating all endogenous variables other than $E$, and finally eliminating $E$. The first step is useful in discussing rebound effects, which are normally defined in terms of variations in $E$. Thus Small and Van Dender measure the rebound effect by substituting the structural equation for vehicle stock into that for travel $(M)$ and solving for $M$. This produces a partially-reduced-form usage equation in which travel is a function of $P_{M}$ (hence of $E$ ) plus exogenous variables. Here we create an analogous usage equation, $\tilde{M}(\cdot)$, which again is a function of $P_{M}$ (hence of $E$ ) and exogenous variables. We do so by substituting the equations for both $V$ and $C$ into that for $M$ :

\footnotetext{
${ }^{3}$ Some research has explicitly considered the separate roles of manufacturers and consumers in adjusting to changes in fuel prices or regulation - see for example Goldberg (1998), Langer and Miller (2008), and Busse, Knittel and Zettelmeyer (2009). Such analyses demonstrate a complex interplay of decision-making. Among other things, they show that changes in fleet fuel efficiency are slowed not only by the stock of existing vehicles, but by the stock of manufacturing assets that are devoted to particular model cars and cannot be quickly changed. Our results confirm that fuel efficiency is the slowest of the three lagged adjustment processes we measure.
} 


$$
\begin{aligned}
M & =M\left[V\left(M, P_{V}, P_{M}, X_{V}\right), P_{M}, C\left(M, K 2, X_{C}\right), K 1, X_{M}\right] \\
& \equiv \tilde{M}\left(P_{M}, P_{V}, K, X_{V}, X_{M}, X_{C}\right) \\
& \equiv \tilde{M}\left(P_{M}, Z\right)
\end{aligned}
$$

where $K=(K 1, K 2)$ and $Z$ designates the variables in function $\tilde{M}(\cdot)$ other than $P_{M}$. (Note $Z$ is exogenous.) As a byproduct, we can also write partially-reduced equations for two other endogenous variables:

$$
\begin{aligned}
& \tilde{V}\left(P_{M}, Z\right)=V\left[\tilde{M}\left(P_{M}, Z\right), P_{V}, P_{M}, X_{V}\right] \\
& \tilde{C}\left(P_{M}, Z\right)=C\left[\tilde{M}\left(P_{M}, Z\right), K 2, X_{C}\right] .
\end{aligned}
$$

We derive the rebound effect in terms of the structural coefficients by differentiating the second of equations (2a) (in logarithmic version) with respect to $\log \left(P_{M}\right)$, evaluating at the solution given by $\tilde{M}$, and solving the result for the elasticity of $\tilde{M}$ with respect to $P_{M}$. This yields: ${ }^{4}$

$$
\varepsilon_{\tilde{M}, P M}=\frac{\varepsilon_{M, P M}+\varepsilon_{M, V} \cdot \varepsilon_{V, P M}}{D}
$$

where each of the $\varepsilon$ 's on the right-hand side is a direct structural elasticity from (1), and where

$$
D=1-\varepsilon_{M, V} \cdot \varepsilon_{V, M}-\varepsilon_{M, C} \cdot \varepsilon_{C, M} .
$$

Thus fuel cost affects usage both directly through $\varepsilon_{M, P M}$ (the elasticity of the first structural equation), and indirectly through changes in the size of the vehicle stock as captured by the product $\varepsilon_{M, V} \cdot \varepsilon_{V, P M}$. (These equations assume $0 \leq D<1$; otherwise, a small shock to the dynamic path of $M$ results in oscillatory or explosive responses, which would be unrealistic and call into question the validity of the empirical specification of the model.)

In the absence of congestion effects, we would have $\varepsilon_{M, C}=0$ and (4a) would become:

$$
D=1-\varepsilon_{M, V} \cdot \varepsilon_{V, M} \text {. }
$$

\footnotetext{
${ }^{4}$ We write the equality as $\log \tilde{M}(\cdot) \equiv \log M[\cdot]$ and note that inside the square brackets is function $V(\cdot)$, which depends on $M$. We take logarithms of both sides and differentiate with respect to $p m \equiv \log \left(P_{M}\right)$, using the chain rule and the fact that each of structural functions $M[\cdot]$ and $V(\cdot)$ depends on $P_{M}$ both directly and indirectly via its dependence on the other endogenous variable. The result is $\varepsilon_{\tilde{M}, P M}=\varepsilon_{M, V} \cdot\left(\varepsilon_{V, P M}+\varepsilon_{V, M} \varepsilon_{\tilde{M}, P M}\right)+\varepsilon_{M, P M}+\varepsilon_{M, C} \varepsilon_{C, M} \varepsilon_{\tilde{M}, P M}$. Solving for $\varepsilon_{\tilde{M}, P M}$ yields (3) and (4a).
} 
Equations (3) and (4b) give the rebound effect as derived by Small and Van Dender (2007). By computing (3) with the alternate denominators as given in (4a) and (4b) and comparing results, one can assess the impact of endogenous congestion on the rebound effect.

Our derivation of induced-demand effects proceeds similarly. We have two capacity variables. The first is road-miles per unit land area, $K 1$; it measures accessibility of destinations and is entered directly in the structural equation (1) for $M$. The second is urban lane-miles per adult, $K 2$; it measures urban road capacity and is assumed to affect travel via congestion. ${ }^{5}$ For each of these, the impact on $M$ is determined similarly by taking the logarithms of (2a), totally differentiating with respect to the logarithm of a capacity variable $K i$ (for $i=1,2$ ), and solving for $\varepsilon_{\tilde{M}, K i} \equiv d(\log M) / d(\log K i)$. The result is:

$$
\varepsilon_{\tilde{M}, K 1}=\frac{\varepsilon_{M, K 1}}{D} ; \quad \varepsilon_{\tilde{M}, K 2}=\frac{\varepsilon_{M, C} \cdot \varepsilon_{C, K 2}}{D}
$$

with $D$ given by (4a). Again, to see what the elasticities would be if congestion had no effect on travel, we would simply use (4b) instead of (4a) to compute $D$.

Policy makers are also interested in knowing whether fuel-efficiency policies would add much to congestion — indeed, as already noted, this has been raised as a potentially serious disadvantage to such policies. In order to investigate this question, we report the elasticity of congestion with respect to fuel efficiency — what we have called the "congestion effect" based on the partially-reduced function (2c). Both the rebound effect and the congestion effect therefore refer to responses to a change in fuel efficiency caused solely by a change in some exogenous variable like those represented as $R_{E}$ and $X_{E}$ in (1). To determine the congestion effect, we differentiate both sides of (2c) with respect to $E$ (recalling that $P_{M}$ is a function of $E$ ), rearrange, and put into elasticity form to obtain:

$$
\varepsilon_{\tilde{C}, E}=-\varepsilon_{C, M} \cdot \varepsilon_{\tilde{M}, P M} \cdot
$$

\footnotetext{
${ }^{5}$ We experimented with a third capacity variable, total lane-miles per adult, in the vehicle stock equation (in lieu of a variable measuring urbanization). This variable took a statistically significant but very small coefficient. We believe urbanization is a theoretically better explanatory variable for the vehicle stock, capturing many aspects of urban form and services that tend to affect vehicle ownership. We also considered whether variable $K 2$ might be endogenous, by estimating the model with a fifth equation explaining $K 2$ as a function of income, state and year dummies, and two political variables equal to that state's number of Representatives and Senators, respectively, belonging to the majority party. This procedure made no important difference to our results, so it is not shown here for simplicity.
} 


\subsection{Fully-reduced-form elasticities}

Although not the focus of this paper, we also report for completeness the elasticities of fuel efficiency, vehicle travel, and fuel consumption with respect to fuel price. These quantities are of interest in considering policies that affect fuel price, and also enable our results to be compared with an additional literature focusing on fuel price elasticities. To do so, we need to fully reduce our system to equations that are functions of exogenous variables only. This is the second step in the process already begun, and it uses the two-equation system consisting of the partially-reduced-form function $\tilde{M}(\cdot)$ from (2a) and the structural equation $E(\cdot)$ from (1). Substituting these into each other and solving for $M$ and $E$ yields the fully-reduced-form functions, which we denote by $M^{*}(\cdot)$ and $E^{*}(\cdot)$. Differentiating those defining equations with respect to fuel price and converting to elasticities, and defining fuel consumption as $F^{*}=M^{*} / E^{*}$, yields:

$$
\begin{aligned}
& \varepsilon_{E^{*}, P F}=\frac{\varepsilon_{E, P F}+\varepsilon_{E, M} \varepsilon_{\tilde{M}, P M}}{1+\varepsilon_{E, M} \varepsilon_{\tilde{M}, P M}} \\
& \varepsilon_{M^{*}, P F}=\varepsilon_{\tilde{M}, P M} \cdot\left(1-\varepsilon_{E^{*}, P F}\right) ; \quad \varepsilon_{F^{*}, P F}=\varepsilon_{M^{*}, P F}-\varepsilon_{E^{*}, P F} .
\end{aligned}
$$

The first of equations (8) describes how the elasticity of mileage is smaller when calculated in a fully-reduced form (which is needed to fully answer questions about effects of fuel prices on travel) than in a partially-reduced form (which is appropriate for questions involving a fleet with fixed average fuel intensity). ${ }^{6}$

\section{Empirical implementation}

We now describe how this theory is implemented in a slightly generalized form, as an estimable econometric system.

\subsection{Econometric model}

We estimate the structural system (1), except that we work with fuel intensity rather than its inverse, fuel efficiency, and we generalize the system to account for dynamics. Thus in the vehicle usage, stock, and intensity equations we include both lagged effects and autoregressive errors. We justify including lagged effects by noting that vehicle usage, ownership, and fleet fuel

\footnotetext{
${ }^{6}$ Equations (8) together imply that $\varepsilon_{F^{*}, P F}=\varepsilon_{\tilde{M}, P M} \cdot\left(1-\varepsilon_{E^{*}, P F}\right)-\varepsilon_{E^{*}, P F}$, also derived by USDOE (1996, p. 5-11).
} 
intensity may only partially change from one period to the next due to behavioral inertia, transaction costs associated with vehicle sales, and other obstructions to adjustment. ${ }^{7}$ For the congestion equation, we assume there is neither autocorrelation nor a lag structure because congestion is assumed to be a technical rather than behavioral relationship.

We specify the equations as linear in parameters with most variables expressed in logarithms. The empirical counterpart of system (1) above is therefore:

$$
\begin{aligned}
(v m a)_{t}= & \alpha^{m} \cdot(v m a)_{i, t-1}+\alpha^{m v} \cdot(v e h)_{t}+\alpha^{m c} \cdot(\text { cong })_{t}+\beta_{1}^{m} \cdot(p m)_{t}+\beta_{K 1}^{m} \cdot(\text { cap } 1)_{t} \\
& +\beta_{3}^{m} X_{t}^{m}+u_{t}^{m} \\
(\text { veh })_{t}= & \alpha^{v} \cdot(v e h)_{t-1}+\alpha^{v m} \cdot(v m a)_{t}+\beta_{1}^{v} \cdot(p v)_{t}+\beta_{2}^{v} \cdot(p m)_{t}+\beta_{3}^{v} X_{t}^{v}+u_{t}^{v} \\
(\text { fint })_{t}= & \alpha^{f} \cdot(\text { fint })_{t-1}+\alpha^{f m} \cdot(v m a)_{t}+\beta_{1}^{f} \cdot(p f)_{t}+\beta_{2}^{f} \cdot(\text { cafe })_{t}+\beta_{3}^{f} X_{t}^{f}+u_{t}^{f} \\
(\text { cong })_{t} & =\alpha^{c m} \cdot(\text { vma })_{t}+\beta_{K 2}^{c} \cdot(\text { cap } 2)_{t}+\beta_{3}^{c} X_{t}^{c}+\varepsilon_{t}^{c}
\end{aligned}
$$

where

$$
u_{t}^{k}=\rho^{k} u_{t-1}^{k}+\varepsilon_{t}^{k}, k=m, v, f
$$

and where we have omitted the subscripts identifying the state. Here, lower-case notation indicates that the variable is in logarithms. Thus vma is the natural logarithm of VMT per adult; veh is the log of number of vehicles per adult; fint is the $\log$ of fuel intensity (i.e., fint = $-\log E$ ); and cong is the log of hours of travel delay per adult. Variable $p f$ is the log of fuel price; hence $\log$ fuel cost per mile, $p m$, is equal to $p f+$ fint. Variable $p v$ is the log of a price index of new vehicles. The variable cafe is a measure of the strength of CAFE regulation; see Small and Van Dender (2007) for a complete description of how this variable is constructed. Variables cap 1 and cap2 are the logarithms of $K 1$ and $K 2$ in system (1), namely, log total road miles per square kilometer and log urban lane miles per adult, respectively. The individual variables in each vector $X_{t}^{k}$ may be in either levels or logarithms. Subscript $t$ designates a year, and $u$ and $\varepsilon$ are error terms assumed to have zero expected value, with $\varepsilon$ assumed to be "white noise".

\subsection{Short-run and long-run elasticities}

\footnotetext{
${ }^{7}$ Our specification ignores the role of expectations (e.g. about future prices), which arguably affect long run elasticities. But since expectations may change over time, it is not clear that explicit treatment of expectations provides better policy-relevant estimates.
} 
Using (9), we can write the empirical counterparts to short-run elasticities (3) and (5)-(7)

as:

$$
\begin{aligned}
& \varepsilon_{\tilde{M}, P M}=\left(\beta_{1}^{m}+\alpha^{m v} \cdot \beta_{2}^{v}\right) / D \\
& \varepsilon_{\tilde{M}, K 1}=\beta_{K 1}^{m} / D ; \quad \varepsilon_{\tilde{M}, K 2}=\alpha^{m c} \cdot \beta_{K 2}^{c} / D \\
& \varepsilon_{\tilde{C}, E}=-\alpha^{c m} \varepsilon_{\tilde{M}, P M} \\
& \varepsilon_{E^{*}, P F}=\frac{-\beta_{1}^{f}-\alpha^{f m} \varepsilon_{\tilde{M}, P M}}{1-\alpha^{f m} \varepsilon_{\tilde{M}, P M}}
\end{aligned}
$$

where

$$
D=1-\alpha^{m v} \cdot \alpha^{v m}-\alpha^{m c} \cdot \alpha^{c m}
$$

Equations (8) remain unchanged. Note that these elasticities describe changes occurring within a given year.

If $\alpha^{f m}<0$ (higher mileage lowers fuel intensity), there are two opposing effects on fuel efficiency in (12). A higher fuel price raises fuel efficiency directly by making consumers desire more to save fuel (i.e., $\beta_{1}^{f}<0$ ), but it also makes them drive less, reducing their need to save fuel $\left(\alpha^{f m}<0\right)$. Much empirical evidence suggests that the first effect is stronger, as we also find.

The $X_{t}^{m}$ term in (9a) contains interactions between $p m$ and other variables, and between congestion and other variables. To facilitate ease in interpreting the coefficients, we normalize these other variables (including pm and cong) at their sample means, so that structural elasticities $\varepsilon_{M, P M}$ and $\varepsilon_{M, C}$ are equal to coefficients $\beta_{1}^{m}$ and $\alpha^{m c}$, respectively, when evaluated at the mean values of variables in our sample. At other values of the interacting variables, we must replace $\beta_{1}^{m}$ and $\alpha^{m c}$ by these structural elasticities, computed as the partial derivatives of (9a), when computing (11)-(13) and later equations in this subsection.

Since we include lagged dependent variables in (9a,b,c), we can also derive formulas for long run elasticities. We do this by rewriting $(9 a, b, c)$ with steady-state values of endogenous variables (i.e., values that do not change over time); this allows us to eliminate the lagged term involving coefficient $\alpha^{k}$ by instead multiplying the left-hand side by (1- $\left.\alpha^{k}\right)$, where $k=m, v, f$. We then carry out the same two-stage procedure as in section 3. (See Appendix E for details.)

In the first stage, we first substitute (E1b) and (E1d) into (E1a), thereby implicitly defining the endogenous variables as partially-reduced steady-state functions of $\mathrm{pm}$ and of 
exogenous variables. We designate these implicit functions as $\operatorname{vma}^{\sim}(\cdot), \operatorname{veh}^{\sim}(\cdot)$, and $\operatorname{cong}^{\sim}(\cdot)$ and differentiate their defining equations with respect to $\mathrm{pm}$, cap1, cap2, or $\log (\mathrm{E})$. We then solve the resulting equations for the desired elasticities. The results are the long run counterparts to (11):

$$
\begin{array}{ll}
\varepsilon_{\tilde{M}, P M}^{L}=\frac{\beta_{1}^{m}+\alpha^{m v} \cdot \overline{\beta_{2}^{v}}}{D^{L}} & \\
\varepsilon_{\tilde{M}, K 1}^{L}=\frac{\beta_{K 1}^{m} ;}{D^{L}} & \varepsilon_{\tilde{M}, K 2}^{L}=\frac{\alpha^{m c} \cdot \beta_{K 2}^{c}}{D^{L}} \\
\varepsilon_{\tilde{C}, E}^{L}=-\alpha^{c m} \varepsilon_{\tilde{M}, P M}^{L} &
\end{array}
$$

where

$$
\begin{array}{rlrl}
D^{L} & =1-\alpha^{m}-\alpha^{m v} \overline{\alpha^{v m}}-\alpha^{m c} \alpha^{c m} & \\
\overline{\alpha^{v m}} & =\frac{\alpha^{v m}}{1-\alpha^{v}} ; & \overline{\beta_{2}^{v}} & =\frac{\beta_{2}^{v}}{1-\alpha^{v}}
\end{array}
$$

and where we assume $0 \leq D^{L}<1$.

In the second stage, we solve explicitly for function $v m a^{\sim}(\cdot)$, substitute it into the steadystate version of (9c), differentiate with respect to log fuel price $p f$ (applying the chain rule), and solve for the long-run elasticity $\varepsilon_{E^{*}, P F}^{L} \equiv \partial(-f i n t) / \partial(p f)$. The result is the long-run counterpart of (12):

$$
\varepsilon_{E^{*}, P F}^{L}=\frac{-\beta_{1}^{f}-\alpha^{f m} \varepsilon_{\tilde{M}, P M}^{L}}{1-\alpha^{f}-\alpha^{f m} \varepsilon_{\tilde{M}, P M}^{L}} .
$$

The reasoning behind equations (8) applies to the long-run elasticities as well:

$$
\begin{aligned}
& \varepsilon_{M^{*}, P F}^{L}=\varepsilon_{\tilde{M}, P M}^{L} \cdot\left(1-\varepsilon_{E^{*}, P F}^{L}\right) \approx \frac{\varepsilon_{\tilde{M}, P M}}{1-\alpha^{m}-\alpha^{m v}} \overline{\alpha^{v m}} \cdot\left(1-\varepsilon_{E^{*}, P F}^{L}\right) \\
& \varepsilon_{F^{*}, P F}^{L}=\varepsilon_{M^{*}, P F}^{L}-\varepsilon_{E^{*}, P F}^{L}
\end{aligned}
$$

where the approximation in (17a) results from neglecting products of small coefficients. ${ }^{8}$

Consider now the implications of equation (17a). It shows how the short-run response of travel to fuel cost, $\varepsilon_{\tilde{M}, P M}$, is modified in the long run in two ways. First, it is amplified by a factor approximately equal to $\left(1-\alpha^{m}-\alpha^{m v} \overline{\alpha^{v m}}\right)^{-1}$ to reflect the full response of the partial

\footnotetext{
${ }^{8}$ With our estimates, the approximation is valid within 1.4 percent. Note also that (14)-(17) reduce to their short-run counterparts, namely (11)-(12) and (8), when $\alpha^{m}=\alpha^{v}=\alpha^{f}=0$.
} 
adjustment mechanisms in vehicle-miles traveled and total vehicle stock. Second, it is diminished by the factor $\left(1-\varepsilon_{E^{*}, P F}^{L}\right)$, which indicates the extent to which the price incentive is dampened by the long-run responsiveness of fuel economy to fuel price. ${ }^{9}$ In our empirical estimates, these two factors are 5.16 and -0.84 , respectively. If we were to simulate the response of system (9) year by year, we could well find that the initial short-run response of mileage to fuel price $\left(\varepsilon_{\tilde{M}, P M}\right)$ is first amplified by the delayed responses working through lagged $M$, but later reduced by the responses of fuel efficiency as they work their way through the system at a somewhat slower pace (since we find empirically that $\alpha^{f}>\alpha^{m}$ ). Intuitively, the initial mileage response is small because people have limited options; over time they can develop more options (e.g. change job locations or travel mode), but simultaneously their incentive to do so diminishes as they replace their fleet with more fuel-efficient vehicles. It could even happen that the long-run elasticity would be smaller in magnitude than the short-run elasticity, although we do not find this. ${ }^{10}$

\subsection{Variables and estimation method}

We use cross-sectional data at the state level for years 1966-2004. Most of our data comes from the Federal Highway Administration's (FHWA) annual Highway Statistics Publications. We provide a brief description of our variables below. Appendix A contains lengthier descriptions and data sources.

We acknowledge that some of the key variables used in this study are inherently difficult to measure on a state-wide basis, leading potentially to measurement error which could bias our estimates. ${ }^{11}$ In particular, we need to consider the vehicle miles traveled (VMT) variable, which

\footnotetext{
${ }^{9}$ If $\varepsilon_{E^{*}, P F}^{L}$ were larger than one, a rising fuel price would even increase driving in the long run, although there is no empirical evidence that this is the case.

${ }^{10}$ To complicate matters still further, the coefficients $\beta_{1}^{m}$ and $\alpha^{m c}$ in these equations change over time because, as noted earlier in this subsection, they are functions of interacting variables such as income. Thus the long-run elasticity is a theoretical construct defining a limit that would eventually be reached if all the interacting exogenous variables remained constant, but is not actually reached in practice. See Small and Van Dender (2005, sect. 6.2) for an example of such year by year simulations.

${ }^{11}$ Schipper et al. (1993) evaluate cross-national estimates of vehicle travel and fuel consumption, arguing that the methods used by various nations to separate travel and fuel consumption among vehicle classes are flawed. This critique includes US national data, although they do find that the FHWA travel estimates (which we use) are consistent with the National Personal Transportation Survey (NPTS), which they regard as a more reliable source. We cannot use NPTS because we require the state-by-state disaggregation performed by FHWA. Our measures of VMT and fuel consumption are for all road users, so faulty separation by vehicle class is less of a concern. We also
} 
appears in all of our model's equations. One source of error in measured VMT arises from the manner in which the data are collected. Individual state DOTs (who initially supply travel estimates to the FHWA) do not directly measure VMT using odometer readings. Instead the states typically estimate travel using traffic counts. ${ }^{12}$ Although the FHWA examines the state reported data for errors and consistency, it does not mandate any particular method for estimating VMT. Given how VMT is calculated, it is not clear whether the FHWA data would more often over-report or under-report vehicle travel. A study of US travel data by Lave (1996) finds close agreement between three independent estimates of annual vehicle travel, including the FHWA data and another data set based on actual odometer readings, wherever they overlap in coverage. This finding suggests that the VMT data are reliable in the later years of our sample.

A second potential problem stemming from measurement error involves our calculation of statewide average fuel intensity, which we obtain by dividing statewide fuel consumption by statewide VMT. Measurement error in VMT will thus also generate error in the fuel intensity variable.

While measurement error clearly exists and must reduce the precision of our estimates, it would bias them only if the errors in the methods used by individual states are correlated over time with the exogenous explanatory variables in our study. Any persistent state-specific error should be removed because we account for state fixed effects in each of the model's equations. Furthermore, although the data generation process may induce some correlated measurement error across endogenous variables such as VMT and fuel efficiency, the three-stage least squares estimator that we use is specifically designed to alleviate the effects of such correlation on estimated coefficients.

Perhaps the greatest danger is that persistent measurement error in a given state (across years) could cause an overestimate of the coefficient in a given equation on the lagged value of the dependent variable. This coefficient is crucial in estimating the relationship between short-

note that their preferred solution, which is to combine survey data from individual households with aggregate data on vehicle fleets, requires numerous assumptions in order to provide the values of aggregate variables and would be unable to provide data for a long panel.

${ }^{12}$ According to TERA, Inc., Greene, and Loebl (1979), 39 states used traffic counts to estimate vehicle travel in 1974 and 1975. Some states instead use measures of statewide fuel consumption along with independent estimates of vehicle fuel efficiency to estimate vehicle travel. The authors find evidence that estimates of VMT based on traffic counts are slightly more variable than those produced using the alternative technique, but do not find any evidence of systematic bias. 
run and long-run elasticities. Thus the rather large difference we find between these elasticities (roughly a factor of five in the VMT equation) might be partly caused by measurement error.

In Section 5.3 below, we discuss the results of a sensitivity analysis where we re-estimate our model using different subsets of the data. In one specification, we exclude potentially problematic data from before 1984, an exclusion that also eliminates the need to impute data. In a second specification, we omit data from Alaska because we noticed inconsistencies across time in the road-mileage variable for that state. Finally, in a third specification, we allow a different coefficient on one of our capacity variables (labeled $K 1$ and described below) for years beginning in 1997 because starting then the FHWA modified its methodology for calculating state road-mileage, resulting in minor changes to the reported data. ${ }^{13}$ The results of the sensitivity analysis, presented in Table 8, indicate that excluding questionable data points or time periods from our sample has little effect on the main set of results.

We now turn to the specific variables used in this study. In the following description, the symbols denoting most variables are followed (in parentheses) by the names of their logarithms as used in the empirical equations. Table 1 provides descriptive statistics, which for ease of interpretation we show un-normalized and in levels rather than logarithms. All monetary variables and price indices are expressed in 1987 dollars.

\section{Dependent variables}

$M(v m a)$ : Vehicles miles traveled, divided by the state's adult population

$V$ (veh): $\quad$ Sum of the number of light duty automobiles and trucks in use, divided by the state's adult population

1/E (fint): Average fuel intensity for the state's fleet of passenger vehicles

$C$ (cong): Total annual hours of delay, divided by the state's adult population (see below for more details)

\section{Independent variables}

$P_{V}(p v)$ : $\quad$ Index of new vehicle prices $(1987=100)$

$P_{F}(p f): \quad$ Price of gasoline (1987 cents per gallon)

\footnotetext{
${ }^{13}$ For details, refer to the discussion at the beginning of Section V in the 1997 edition of Highway Statistics (US FHWA, 1998).
} 
K1 (cap1): Total length of roads divided by state land area (miles per square mile)

K2 (cap2): Urban lane miles per adult

$R_{E}$ (cafe): Measure of the strength of CAFE regulation, which we define as the difference between desired and mandated fleet vehicle fuel efficiency. We estimate actual fuel efficiency for years 1966-1977, and then use the estimated coefficients to predict desired fuel efficiency for years 1978 and beyond. The variable cafe is defined as the difference between the logarithms of desired and mandated fuel efficiency, truncated below at zero. See Appendix B in Small and Van Dender (2007) for a more complete description.

$X_{M}, X_{V}, X_{E}$ : See Table 1, the appendices, and Small and Van Dender (2007) for a full list and descriptions. Variables $X_{M}$ include $\mathrm{pm}^{2}$; interactions between normalized $p m$ and other variables, which here include normalized log income per capita (inc) and normalized log congestion (cong); and the interaction pm·cong. Each equation includes state fixed effects, i.e., a distinct constant term for each state (including District of Columbia).

$X_{C}$ : $\quad$ Population density (a proxy for the physical nature of the roads), and the percentage of vehicles that are trucks. The congestion equation includes both state fixed effects and year fixed effects.

\section{Derived endogenous variable}

$P_{M}(p m): \quad$ Per-mile fuel cost of driving $\left(=P_{F} / E\right)$

\section{Congestion measure}

We construct our measure of travel delay using data from the annual report on traffic congestion constructed by Shrank and Lomax of the Texas Transportation Institute (TTI) - see e.g. Shrank and Lomax (2004). TTI has estimated congestion for 85 large urbanized areas, starting in 1982, using data from the Highway Performance Monitoring System database of the US Federal Highway Administration.

The TTI measure of congestion that we use is annual travel delay, which is simply the aggregate amount of time lost due to congested driving conditions. TTI has sometimes been criticized for using this measure as an index of the nation's congestion problem because it 
includes congestion that would remain in an optimized system. Irrespective of the validity of this criticism, for our purposes the TTI measure is appropriate because it describes the experience of the typical driver. The measure is constructed largely from assumed speed-flow relationships, but supplemented with speed observations on specific roads. As with other data in our study, it is probably more reliable in the more recent years.

We aggregate congestion delay in all covered urbanized areas to the level of a state, then divide by the state's adult population to create a per-adult delay measure. So we implicitly assume that congestion outside these 85 urban areas is negligible, an assumption we believe to be warranted because congestion in the US is vastly more costly to drivers in large than small urban areas. Furthermore, since we measure data at the state level, it is appropriate that the congestion in the larger urbanized areas is, for most states, diluted by the lack of congestion elsewhere in our equations predicting statewide travel response. A further advantages of our use of total delay, rather than some measure of average congestion, is that it is relatively unaffected by possible differences in how boundaries are drawn for urban areas in different states.

For the 14 urbanized areas that cross one or more state borders, we apportion their congestion to the constituent states based on population data, which exists for the 1980, 1990, and 2000 censuses; we linearly interpolate for intermediate years, and extrapolate the 1990-2000 trend to 2004. Appendix B provides more details.

\section{Multiple imputation procedure}

The congestion and one of the highway capacity measures in the data set are available only as of 1982. Because other variables are available as far back as 1966, we do not want to restrict the entire study to this shorter time period. So we develop an imputation method to "predict" the congestion data for the years 1966-1981. Because this introduces an additional source of error in a dependent variable, we use the multiple imputation procedure of Rubin (1987) in order to generate consistent estimates of coefficients and their standard errors. The procedure follows Brownstone and Steimetz (2005) and is explained in Appendix C.

The multiple imputation procedure enables us to incorporate the missing data in a statistically valid and computationally tractable way, providing measures of statistical precision and hypothesis tests with the usual interpretations. There is a cost in precision of using imputed rather than precisely measured data: the standard deviations of estimated parameters, derived in 
Appendix C, are larger than they otherwise would be. As an additional check we re-estimated the model using data from 1984-2004, which eliminates the need for any imputation of the congestion or urban lane-mileage data. The estimates, presented in Table 8 and Table D2, are less precise but are otherwise quite similar to our key set of estimates.

\section{Instrumental Variables and Exclusion Restrictions}

We estimate the system using three-stage least squares (3SLS), which is an instrumental variables estimator that normally uses all exogenous variables of the system as instruments. The 3SLS method makes use of correlations among disturbances across our four equations to obtain more efficient parameter estimates than single-equation methods such as two-stage least squares. Such correlations may be expected due to common factors that influence two or more related choices but that we do not explicitly include. Because our equations include lagged endogenous variables, autocorrelation, and certain non-linear transformations of variables, we add to the set of instruments one lagged value of each exogenous variable, two lagged values of each endogenous variable, and predicted values for non-linear combinations of endogenous variables (the latter based on reduced-form equations explaining each endogenous variables in terms of all exogenous variables). The rationale for these choices is explained by Small and Van Dender (2007).

Our judgments on which exogenous variables to include in each equation (the exclusion restrictions) are discussed in Small and Van Dender (2007) in the case of the first three equations. In the case of the congestion equation, we reason that congestion is a technical rather than a behavioral phenomenon and therefore many factors that might explain it should do so through the channels of traffic and road capacity. Hence we include just four explanatory variables for congestion: two measures of traffic (urban vehicle-miles per adult ${ }^{14}$ and the percentage of vehicles that are trucks) and two measures of capacity (urban lane miles per adult and population density, the latter viewed as a proxy for the physical nature of the roads).

\footnotetext{
${ }^{14}$ This variable is approximated as VMT per adult multiplied by percent of population in urban areas. Taking its logarithm gives $\log (\mathrm{VMT}$ per adult) + log (Urban) $\equiv v m a+$ urban. We tried allowing vma and urban to enter as two separate variables, but doing so imparted some instability to the estimation.
} 


\section{Estimation results}

In this section, we present the estimation results, derive some key implications, and provide a detailed account of the sources of difference between our induced-demand elasticities and those more commonly found in the literature, in particular those by Noland (2001).

\subsection{Key results}

Table 2 shows the results for the structural equation (9a) explaining vehicle miles traveled per adult. We estimate all of the coefficients with a high degree of precision, obtaining plausible signs and magnitudes. The coefficients for the per-mile cost of driving and its interactions are all statistically significant and generally comparable in magnitude to those found by Small and Van Dender (2007). ${ }^{15}$

The coefficient for travel delay per adult (cong) is statistically significant and negative, suggesting that all else equal, congestion decreases vehicle usage for a state and year with sample-average income and per-mile driving cost. Furthermore, the coefficient for congestion interacted with income is negative, implying that congestion has a larger negative impact on vehicle usage when income is above average. For example, raising income to that for the average state in 2004, compared to its average over the entire sample, causes the effect of congestion on VMT to be 1.739 times as large as indicated by the coefficient of cong in Table $2 .{ }^{16}$ We find this plausible since people with higher incomes have a higher value of time and are more easily dissuaded from driving when faced with congestion costs. ${ }^{17}$ Nevertheless, our estimates suggest that the elasticity of vehicle usage with respect to congestion is small: approximately -.009 in the

\footnotetext{
${ }^{15}$ The interacted variable $p m^{*}$ Urban is omitted here for simplicity because it is not statistically significant when included and it played an unimportant role in the earlier results

${ }^{16}$ Based on the calculation $(-0.0092-0.0244 \cdot 0.280) /(-0.0092)=1.739$, where 0.280 is the difference between inc averaged over 2004 and inc averaged over 1966-2004. Recall that inc is log of real per capita income.

${ }^{17}$ We also obtained a negative coefficient on the interaction between congestion and the per-mile cost of driving. This result has two separate interpretations. First, it suggests that the effect of the per-mile cost of driving on travel increases with the level of congestion, which is contrary to our prior beliefs. The other interpretation is that exogenous increases in traffic congestion have a greater deterrent effect on vehicle travel in states with higher fuel costs. This result seems reasonable, as vehicles in stop and go traffic are less fuel-efficient, and this differential is greater when fuel costs are high. Our model cannot determine which interpretation is more appropriate because it lacks an explicit depiction of how operating costs respond to congestion.
} 
short run and -0.045 in the long run. ${ }^{18}$ We attribute the small elasticity to the fact that our measure of travel is statewide VMT, while congestion itself is a localized phenomenon.

The ordinary income-elasticity of vehicle travel is 0.10 in the short run and 0.50 in the long run (at average values of interacted variables). We find roughly a 4 percent reduction in VMT in 1974 and 1979 compared to other years, all else equal. As in Small and Van Dender (2007), we find that the rebound effect diminishes in magnitude with income and increases in magnitude with fuel costs. Other results are also similar to Small and Van Dender's.

We obtain a large and significant coefficient for lagged VMT, giving support for a partial adjustment process. The autocorrelation coefficient rho is small, even though quite precisely estimated, leading us to believe we have not omitted any important autocorrelated independent variables. Still, we are reluctant to push our data into measuring yet further details of the dynamic processes at work. For example, we cannot be sure that the partial adjustment process takes place at the same rate when different exogenous variables are varied, as is assumed in our specification. Also, as noted earlier, there is some danger that persistence in measurement errors of VMT may have caused an overestimate of the coefficient for lagged VMT, and hence of the ratio of long-run to short-run elasticities. To the extent this is true, our key findings of small elasticities would be further strengthened.

Table 3 shows the results from estimating the vehicle stock equation. We find that the amount of driving ( $\mathrm{vma}$ ), urbanization, and number of licensed drivers all have significant effects on the vehicle stock. We do not find significant effects for the price of a new vehicle, the interest rate, per capita income, or the per-mile cost of driving. As would be expected, there is evidence for a slow turnover in the vehicle stock, as the coefficient for lagged vehicle stock is strong and significant. Again, we obtain a low value for rho, the autocorrelation coefficient.

Table 4 shows the results for the fuel intensity equation. We obtain the expected signs and significant coefficients for most of the variables in this equation. We find that CAFE regulation, the oil shocks of 1974 and 1979, and the price of fuel impact fuel intensity substantially and negatively. As in the other equations, the results suggest we have correctly controlled for dynamics: we obtain a small value for the autocorrelation coefficient rho. Since fuel intensity is mainly a property of the vehicle stock, factors that hinder adjustment of the

\footnotetext{
${ }^{18}$ The short-run elasticity is approximately the coefficient on cong in Table 2. The long run elasticity is approximately this coefficient divided by $\left(1-\alpha_{m}\right)=(1-0.7947)$.
} 
vehicle stock will also prevent full adjustment of fuel intensity to its desired level, which explains the large coefficient for lagged fuel intensity.

Table 5 presents the results from the congestion equation. We include year fixed effects, as noted earlier, but do not report their coefficients in order to simplify the table. (All four equations include state fixed effects, also not reported for simplicity.) As expected, we find that increased urban road capacity (urban-lane-miles/adult) reduces congestion while higher traffic volumes (vma) increase congestion. Furthermore, we find that higher population density increases congestion, presumably because it decreases the effective capacity of a lane-mile of highway, and also because when population density is growing it is likely to produce a mismatch between the locations of population and of roads. As expected, a higher fraction of trucks also increases congestion.

Table 6 presents some elasticities computed from the results presented in Tables 2-5 using the equations in section 3 . We find that induced demand operates through both of the posited channels. If total road mileage is expanded, so that both channels are applicable, the short-run elasticity (evaluated at sample-average values of variables) is 0.032. About 59 percent of this comes from increased accessibility and the other 41 percent from congestion relief. Longrun induced-demand elasticities, calculated from equations (16), are about four times higher. Interaction effects imply that the elasticity working through congestion relief rose modestly and gradually in magnitude, reaching the value 0.018 by 2004 (Table 6), due mainly to rising incomes as captured by the coefficient on cong*inc in Table 2. The induced-demand elasticity for accessibility is constant, so the two channels are of approximately equal magnitudes if measured in 2004.

We also estimated the fraction of VMT growth attributable to road-capacity expansions. Using the results from our preferred specification (presented in Tables 2-5) we evaluated a counterfactual scenario in which the level of lane and road miles were held constant between 1998 and 2004, while all of the other exogenous variables took their historic values. Using these inputs, we iteratively solved our simultaneous model out to 2004. Comparing actual VMT in 2004 to counterfactual VMT, we found that road-capacity expansions accounted for 6.57 percent of the annualized VMT growth rate.

Our estimate of the average rebound effect across the states and years in our sample, stated as a positive percentage, is $4.7 \%$ in the short run and $24.1 \%$ in the long run. (That is, the 
short- and long-run VMT elasticities with respect to fuel cost are -0.047 and -0.241.) As already noted, this effect declines drastically in magnitude over the duration of our sample, due mainly to rising real incomes. It also rises in magnitude with fuel costs (not shown in the table). Specifically, the coefficient on $\mathrm{pm}^{*} \mathrm{pm}$ in Table 2 implies that a 10 percent increase in the permile fuel cost of driving translates into approximately a 0.25 percentage-point increase in the short-run rebound effect. These results are of similar magnitude and more precisely estimated than the results found by Small and Van Dender (2007). We estimate the "congestion effect" the elasticity of congestion (travel delay) with respect to fuel efficiency - to be 0.022 in the short run and 0.111 in the long run. The overall price elasticity of fuel consumption, which accounts for changes in both VMT and fuel efficiency in response to fuel price, is estimated at -0.075 and -0.361 in the short and long runs respectively. Because this elasticity incorporates the VMT elasticity, it also declines to a smaller value in later years due to increased incomes. In all cases our elasticity estimates are significantly different from zero.

\subsection{Comparison with other estimates of induced demand}

Our estimate of the induced-demand effect - about 0.16 in the long run - is at the low end of the range expected from our review of the literature. We expect a low value for the part of induced demand arising from capacity expansion, because we consider total traffic on a statewide level and most of the effects of capacity expansion would occur only in highly congested urban areas.

Other possible explanations for differences from other estimates include differences in control variables, time spans, capacity measures, and overall model structure compared to other studies. To test some of these possibilities, we take advantage of the fact that Noland (2001) uses a panel structure identical to ours, and data that overlap considerably with ours. We therefore first replicate the estimate of Noland (2001) that we consider the most reliable - namely, that explaining VMT per capita (non-local roads only) and including the lagged dependent variable as an explanatory variable. We then re-estimate the same model while systematically changing various features of its specification in the direction of our model - first by quantifying variables on a per adult rather than per capita basis, then extending the time period (using multiple imputations where necessary), and finally adding our other control variables and observations for the District of Columbia. 
Table 7 compares selected results in terms of the short-run induced demand effect. Rows numbered 1-6 show results from single-equation specifications for four different time periods; the capacity coefficient in these specifications gives the short-run elasticity of VMT with respect to road capacity. Row 7 shows results from our four-equation model, using two distinct measures of capacity. In all cases, the coefficient of lagged VMT is between 0.729 and 0.829, implying that the long-run elasticity is 3.7 to 5.1 times the short-run elasticity. The full set of parameter estimates for each single-equation specification shown in Table 7 (along with some other similar specifications) is presented in Appendix D.

Rows 1 and 2 of Table 7 present our estimates using Noland's specification that includes state dummy variables (excluding data from the District of Columbia, as does he), for time period (1984-1996). We closely replicate his results when we deflate income using the GDP deflator, as did he. When we switch to our measure of real income, which is deflated by the consumer price index (CPI), the coefficient of road capacity falls substantially, from 0.138 to 0.086. This sensitivity is surprising, but may indicate that omitted variables (evidently correlated differently to the two measures of real income) are adversely affecting this rather simple specification. 19

Rows labeled 3-6 of Table 7 change the specification from that in the second row in small cumulative steps. In row 3, variables are measured per adult instead of per capita; the estimated induced-demand effect drops from to 0.086 to 0.078 . In row 4 , we see that extending the time period four years earlier and eight years later lowers the coefficient by more than half, to 0.036. For the regression presented in row 5, we use multiple imputations in order to extend the data set backward in time to year 1966, since values for non-local lane-miles are not observed before 1980; this lowers the induced demand estimate a bit more, to 0.031. The specification in row 6.a includes other exogenous variables from our vehicle-miles traveled equation; this lowers the estimate by more than a factor of two, to 0.012. We also tested the sensitivity of our results from this richer specification to deflating the income variable by GDP instead of the CPI, and we

\footnotetext{
${ }^{19}$ This explanation seems possible because using our data, real income and the road-capacity measured are somewhat (negatively) correlated, with correlation coefficient -0.58 . One other small difference between row 1 and other rows is that the Bureau of Economic Analysis has updated income data slightly since the time when Noland extracted them; except in row 1, we have used the updated series. We are grateful to Robert Noland for sending us his original data, enabling us to perform this comparison and to diagnose the reasons for differences between specifications.
} 
obtain the same capacity coefficient in both cases. This result supports our claim that omitted variables may adversely affect the estimates in the sparse specification.

Results from our four-equation model, estimated with three-stage least squares, are repeated from earlier tables in row 7 . The total induced demand effect of 0.032 from increasing total road mileage is very close to the values in rows 4-5 of the table, while the portion of induced demand arising just from urban capacity is very close to the value in row 6 . Thus while recognizing that the models are not strictly comparable, we think that most of the differences between our results and Noland's arise from our using more control variables and a much longer time period, offset somewhat by our distinguishing between two types of induced demand. We also note that in our results, the total induced-demand effect rises in magnitude by 11-16 percent by the end of the sample period, to 0.037 in the short run and 0.186 in the long run, as shown in the last two columns of Table 6.

\subsection{Sensitivity Analysis}

To test the sensitivity of the results to recognized data problems and to our imputation procedure, we estimated three different versions of our base model. We limit the analysis to the

problems most likely to affect our key results. Selected results from this analysis are presented in Table 8.

One problematic state was Alaska, which had inconsistent road-mileage data, with the reported lane-mileage value increasing and decreasing by an implausible amount between 1982 and 1984. Omitting data from Alaska had a small affect on the key results, reducing the short-run rebound effect from 4.7 percent to 4.2 percent and the total induced-demand effect from 0.032 to 0.025 .

We also examined a potential problem with the road-mileage data. In 1997, the FHWA changed its methodology slightly for calculating state road mileage, which is one of our capacity variables used for analyzing induced demand. To account for this change, we estimated a specification of the model that allows a different coefficient on that capacity variable beginning in 1997 (in the VMT equation). As Table 8 shows, the resulting coefficient is statistically indistinguishable from zero, suggesting the change in methodology did not affect how this variable influences travel. 
Using multiple imputations to account for missing data in the earlier years has a modest effect on the key results. For the most part, the point estimates are quite similar, but have larger standard errors. Finally, we estimated the model while restricting our sample to the years 19842004, the longest time period for which we do not have to impute any data. Table 8 shows the results, with variables evaluated at their 1984-2004 mean values. Restricting the sample causes the short-run rebound effect to rise (from 2.8\% to 4.8\%); but due to a compensating change in the coefficient of lagged VMT, ${ }^{20}$ the long-run rebound effect changes only a little (from $14.3 \%$ to $15.9 \%)$. As for the total induced-demand effect of expansion in total road mileage, restricting the sample changes the short-run elasticity value only slightly (from 0.031 to 0.033 ) while it decreases the long-run elasticity substantially (from 0.159 to 0.114 ). A larger set of results is presented in Appendix Table D2.

The upshot of this sensitivity analysis is that most results change very little, the exception being that certain long-run elasticities become even smaller - thus if anything adding further support to our overall findings. However, the 1984-2004 results suffer from considerably less precision in many of its estimated coefficients (see Appendix Table D2), as expected from eliminating nearly half the data, so we have more confidence in our baseline results.

\section{Conclusion}

We have shown that including a measure of congestion in an aggregate transportation demand model is feasible and that doing so helps clarify at least two phenomena of interest to methodology and policy. First, we can confirm an additional pathway in the responsiveness of travel to fuel prices or to fuel-efficiency regulations, namely, any increase in travel that otherwise would occur will be dampened slightly by the additional congestion it creates. Second, we can distinguish between two pathways by which induced demand occurs: one through the ability of new infrastructure to make more locations easily accessible, the other through its ability to reduce urban congestion.

Our estimates of induced demand are lower than most others, partly due to our use of a longer time period and more control variables. But mainly we think it is due to our focus on a state-wide aggregate measure of vehicle travel, which of course dilutes the local impact of any increased capacity. Thus, our estimates do not necessarily conflict with results showing dramatic 
increases in use of particular facilities when they are expanded, and both types of estimates are needed to fully describe the ancillary effects of policies that affect congestion.

Quantitatively, we find the influence of congestion to be quite small, at least on the statewide aggregate measures that we use. The congestion pathway lowers the long-run rebound effect, as calculated with variables at their 2004 average values, from 9.2 percent to 9.0 percent (i.e., the elasticity is lowered in magnitude from -0.092 to -0.090). As for the estimated magnitude of the rebound effect itself, our estimates are very close to those found by Small and Van Dender (2007) using a three-equation model and data through 2001. Like them, we find a strong negative dependence of the rebound effect on real income and a smaller positive effect on fuel cost, with the net result that it was considerably smaller in the later years of the sample than when measured over the sample average.

Thus our methodology illustrates some ways that feedback effects may be identified, measured, and separated into components. Such feedback effects typically show up as unintended consequences of policies, and thus tend to be viewed as problems. However, it is worth remembering that these unintended consequences have both costs and benefits - indeed, travel itself is a benefit, which is why we have transportation systems in the first place - so a full normative analysis of policies that have feedback effects requires a comprehensive measure of welfare. We believe that by measuring the specific pathways by which feedback effects work, the methods developed here will facilitate more complete and accurate policy evaluations.

\section{Acknowledgements}

We thank the editor and two referees for helpful comments. In addition, we thank Robert Noland for sharing his original data set. The University of California Transportation Center and the UC Irvine Institute for Transportation Studies supported this research. 


\section{References}

Brownstone, D.,Valletta, R., 2001. The bootstrap and multiple imputations: harnessing increased computing power for improved statistical tests. Journal of Economic Perspectives. 15(4), 129-141.

Brownstone, D., Steimetz, S., 2005. Estimating commuters' value of time with noisy data: a multiple imputation approach. Transportation Research Part B: Methodological. 39(10), 865889.

Busse, M.R., Knittel, C.R., Zettelmeyer, F., 2009. Pain at the pump: how gasoline prices affect automobile purchasing in new and used markets. Working paper, University of California at Davis, February. http://www.econ.ucdavis.edu/faculty/knittel/papers/gaspaper_latest.pdf

Cervero, R., 2003. Road expansion, urban growth, and induced travel: a path analysis. Journal of the American Planning Association. 69(2), 145-163,

Cervero, R., Hansen, M., 2002. Induced travel demand and induced road investment: a simultaneous equation analysis. Journal of Transport Economics and Policy. 36(3), 469-490.

Dargay, J., 2007. The effect of prices and income on car travel in the UK. Transportation Research Part A: Policy and Practice. 41(10), 949-960.

Downs, A., 1962. The law of peak-hour expressway congestion. Traffic Quarterly. 16(3), 393409.

Fulton, L.M., Noland, R.B., Meszler, D.J., Thomas, J.V., 2000. A statistical analysis of induced travel effects in the U.S. mid-Atlantic region. Journal of Transportation and Statistics. 3(1), $1-14$.

Goldberg, P.K., 1998. The effects of the Corporate Average Fuel Economy Standards. Journal of Industrial Economics. 46(4), 1-33.

Goodwin, P.B., 1996. Empirical evidence on induced traffic, a review and synthesis. Transportation. 23(1), 35-54.

Goodwin, P.B., Dargay, J., Hanly, M., 2004. Elasticities of road traffic and fuel consumption with respect to price and income: a review. Transport Reviews. 24(3), 275-292.

Graham, D.J., Glaister, S., 2004, Road traffic demand elasticity estimates: a review. Transport Reviews. 24(3), 261-274.

Greene, D.L., 1992. Vehicle use and fuel economy: how big is the 'rebound' effect?. Energy Journal. 13(1), 117-143.

Greene, D.L., Kahn, J.R., Gibson, R.C., 1999. Fuel economy rebound effect for U.S. household vehicles. Energy Journal. 20(3), 1-31.

Greening, L.A., Greene, D.L., Difiglio, C., 2000. Energy efficiency and consumption - the rebound effect - a survey. Energy Policy. 28(6-7), 389-401.

Hanson, M., Huang, Y., 1997. Road supply and traffic in California urban areas. Transportation Research Part A: Policy and Practice. 31(3), 205-218. 
Haughton J., Sarkar, S., 1996. Gasoline tax as a corrective tax: estimates for the United States, 1970-1991. Energy Journal. 17(2), 103-126.

Holden, D.J., 1989. Wardrop's third principle: urban traffic congestion and traffic policy. Journal of Transport Economics and Policy. 23(3), 239-262.

Jones, C.T., 1993. Another look at U.S. passenger vehicle use and the 'rebound' effect from improved fuel efficiency. Energy Journal. 14(4), 99-110.

Langer, A., Miller, N., 2008. Automobile prices, gasoline prices, and consumer demand for fuel economy. Economic Analysis Group Discussion Paper EAG 08-11, Antitrust Division, US Department of Justice, December.

Lave, C.A., 1996. What really is the growth of vehicle usage?. Transportation Research Record. 1520, 117-121.

Mannering, F.L., 1986. A note on endogenous variables in household vehicle utilization equations. Transportation Research Part B: Methodological. 20(1), 1-6.

Mokhtarian, P.L., Samaniego, F.J., Shumway, R.H., Willits, N.H., 2002. Revisiting the notion of induced traffic through a matched-pairs study. Transportation, 29(2), 193-220.

Noland, R.B., 2001. Relationships between highway capacity and induced vehicle travel. Transportation Research Part A: Policy and Practice. 35(1), 47-72.

Pickrell, D., Shimek, P., 1999. Growth in motor vehicle ownership and use: evidence from the Nationwide Personal Transportation Survey. Journal of Transportation and Statistics. 2(1), 117.

Portney, P.R., Parry, I.W.H., Gruenspecht, H.K., Harrington, W., 2003. The economics of fuel economy standards. Journal of Economic Perspectives. 17(4), 203-217.

Rubin, D., 1987. Multiple Imputation for Nonresponse in Surveys. Wiley, New York, NY.

SACTRA, 1994. Trunk roads and the generation of traffic. Standing Advisory Committee on Trunk Road Assessment. London: Her Majesty’s Stationery Office.

Schipper, L., Figueroa, M.J., Price, L., Espey, M., 1993. Mind the gap: the vicious circle of measuring automobile fuel use. Energy Policy. 21(12), 1173-1190.

Schrank D., Lomax, T., 2004. The 2004 Urban Mobility Report. College Station, TX: Texas Transportation Institute.

Small, K.A., Van Dender, K., 2005. A study to evaluate the effect of reduced greenhouse gas emissions on vehicle miles traveled. Final report for the California Air Resources Board, ARB Contract Number 02-336 (March).

Small, K.A., Van Dender, K., 2007. Fuel efficiency and motor vehicle travel: the declining rebound effect. Energy Journal. 28(1), 25-51.

Small, K.A., Verhoef, E.T., 2007. The Economics of Urban Transportation. Routledge. London and New York.

Smeed, R.J., 1968. Traffic studies and urban congestion. Journal of Transportation Economics and Policy. 2(1), 33-70. 
TERA, Inc., Greene, D.L., Loebl A.S., 1979. Vehicle-miles of travel statistics, lifetime vehiclemiles of travel, and current state methods of estimating vehicle-miles of travel. Report ORNL-TM-6327, Oak Ridge, Tennessee: Oak Ridge national Laboratory and Washington, D.C.: National Technical Information Service.

Thomson, J.M., 1977. Great Cities and their Traffic. Gollancz, London.

West, S.E., 2004. Distributional effects of alternative vehicle pollution control policies. Journal of Public Economics. 88(3-4), 735-757.

US DOE, 1996. Policies and Measures for Reducing Energy Related Greenhouse Gas Emissions: Lessons from Recent Literature. Report No. DOE/PO-0047, US Department of Energy, Office of Policy and International Affairs, Washington, D.C.

US FHWA, 1998. Highway Statistics 1997. Report No. FHWA-PL-98-020, US Federal Highway Administration, Washington, D.C. 


\begin{tabular}{|c|c|c|c|c|c|}
\hline \multicolumn{6}{|c|}{ Table 1. Descriptive Statistics } \\
\hline Name & Definition & Mean & Std. Dev. & Min & Max \\
\hline Vma & VMT per adult (000) & 11.16 & 2.67 & 4.75 & 24.11 \\
\hline Vehstock & Vehicles per adult & 1.01 & 0.19 & 0.45 & 1.74 \\
\hline Fint & Fuel intensity (gal/mile) & 0.06 & 0.01 & 0.03 & 0.09 \\
\hline Cong & Total hours of delay per adult & 6.81 & 8.14 & 0.00 & 47.14 \\
\hline $\mathrm{Pf}$ & Price of fuel (dollars/gal) & 1.08 & 0.23 & 0.60 & 1.95 \\
\hline Pm & Fuel price per mile (cents/mile) & 6.62 & 2.29 & 2.78 & 14.20 \\
\hline Inc & Income per capita (000) & 14.94 & 3.50 & 6.45 & 30.76 \\
\hline Lane-miles/adult & Lane miles per adult & 0.08 & 0.09 & 0.00 & 0.77 \\
\hline Urban-lane-miles/adult & Urban lane miles per adult & 0.01 & 0.00 & 0.00 & 0.02 \\
\hline Road miles/land area & Road miles per sq. mile of land area & 2.09 & 2.71 & 0.01 & 25.01 \\
\hline Pop/adult & State population per adult & 1.41 & 0.09 & 1.23 & 1.74 \\
\hline Urban & Fraction of population living in MSA & 0.71 & 0.19 & 0.29 & 1.00 \\
\hline $\mathrm{Pv}$ & Price index for new vehicles & 1.04 & 0.21 & 0.70 & 1.49 \\
\hline Interest & Interest rate for new car loans (\%) & 10.43 & 2.72 & 5.17 & 16.49 \\
\hline licenses/adult & Licensed drivers per adult & 0.91 & 0.08 & 0.60 & 1.17 \\
\hline Percent trucks & Percent of vehicles that are trucks & 0.30 & 0.12 & 0.04 & 0.64 \\
\hline Pop. density & Population density (persons/sq. mile) & 140.99 & 563.95 & 0.18 & 4948.96 \\
\hline
\end{tabular}

Notes: Variable names with capitalized names are presented in levels and are not normalized. All monetary values are in constant 1987 dollars. 


\begin{tabular}{|c|c|c|}
\hline \multicolumn{3}{|c|}{ Table 2. Vehicle Miles Traveled Equation } \\
\hline Variable & Coefficient & Std. Error \\
\hline rho & $-0.0757(* * *)$ & 0.0230 \\
\hline constant & $1.8472(* * *)$ & 0.1253 \\
\hline inc & $0.1031(* * *)$ & 0.0136 \\
\hline cong & $-0.0092(* * *)$ & 0.0026 \\
\hline cong*inc & $-0.0244 \quad(* * *)$ & 0.0059 \\
\hline cong*pm & $-0.0124 \quad(* * *)$ & 0.0031 \\
\hline $\mathrm{d} 7479$ & $-0.0435(* * *)$ & 0.0035 \\
\hline trend & $0.0010(* * *)$ & 0.0003 \\
\hline vma(t-1) & $0.7947(* * *)$ & 0.0126 \\
\hline vehstock & $0.0340(* * *)$ & 0.0096 \\
\hline pm & $-0.0474(* * *)$ & 0.0043 \\
\hline $\mathrm{pm} * \mathrm{pm}$ & $-0.0251 \quad(* * *)$ & 0.0074 \\
\hline $\mathrm{pm} *$ inc & $0.0635(* * *)$ & 0.0156 \\
\hline pop/adult & $0.2663(* * *)$ & 0.0431 \\
\hline Urban & $-0.1626(* * *)$ & 0.0526 \\
\hline road-miles/land-area & $0.0186 \quad(* *)$ & 0.0076 \\
\hline Observations & 1938 & \\
\hline Adjusted $\mathrm{R}^{2}$ & 0.982 & \\
\hline
\end{tabular}

Notes: $\left({ }^{* * *}\right),\left({ }^{* *}\right)$ and $(*)$ indicate that the coefficient is statistically significant at the $1 \%, 5 \%$ and $10 \%$ level respectively. We estimate this equation using non-linear least squares. We adjust the point estimates and standard errors using a multiple imputation procedure. 


\begin{tabular}{lrrr}
\hline \multicolumn{4}{c}{ Table 3. Vehicle Stock Equation } \\
\hline Variable & Coefficient & Std. Error \\
\hline rho & $-0.1146 \quad(* *)$ & 0.0263 \\
constant & $-0.4355 \quad(*)$ & 0.1661 \\
pv & 0.0211 & 0.0334 \\
interest & 0.0028 & 0.0046 \\
inc & 0.0215 & 0.0166 \\
Urban & $-0.1072 \quad(* * *)$ & 0.0582 \\
licenses/adult & $0.0625 \quad(* *)$ & 0.0199 \\
trend & -0.0002 & 0.0007 \\
vehstock(t-1) & $0.8697 \quad(* * *)$ & 0.0146 \\
vma & $0.0452 \quad(* *)$ & 0.0167 \\
pm & -0.0010 & 0.0070 \\
\hline & & \\
Observations & 1938 & \\
Adjusted R ${ }^{2}$ & 0.958 & \\
\hline
\end{tabular}

Notes: $(* * *),(* *)$ and $(*)$ indicate that the coefficient is statistically significant at the $1 \%, 5 \%$ and $10 \%$ level respectively. We estimate this equation using non-linear least squares. We adjust the point estimates and standard errors using a multiple imputation procedure. 


\begin{tabular}{|c|c|c|}
\hline \multicolumn{3}{|c|}{ Table 4. Fuel Intensity Equation } \\
\hline Variable & Coefficient & Std. Error \\
\hline rho & $-0.1468 \quad(* * *)$ & 0.0224 \\
\hline constant & $-0.1619 \quad(* *)$ & 0.0779 \\
\hline$(\mathrm{vma}+\mathrm{pf})$ & $-0.0304(* * *)$ & 0.0062 \\
\hline inc & -0.0078 & 0.0159 \\
\hline fint(t-1) & $0.8465(* * *)$ & 0.0127 \\
\hline trend66-73 & 0.0008 & 0.0010 \\
\hline trend74-79 & $-0.0038 \quad(* * *)$ & 0.0009 \\
\hline trend80+ & $-0.0024(* * *)$ & 0.0004 \\
\hline d7479 & $-0.0108 \quad(* *)$ & 0.0046 \\
\hline Urban & $-0.1118 \quad(*)$ & 0.0576 \\
\hline cafe & $-0.0910 \quad(* * *)$ & 0.0108 \\
\hline pop/adult & -0.0249 & 0.0638 \\
\hline Observations & 1938 & \\
\hline Adjusted $\mathrm{R}^{2}$ & 0.962 & \\
\hline \multicolumn{3}{|c|}{$\begin{array}{l}\text { Notes: }\left({ }^{* *}\right),\left({ }^{*}\right) \text { and }(*) \text { indicate that the coefficient is } \\
\text { statistically significant at the } 1 \%, 5 \% \text { and } 10 \% \text { level } \\
\text { respectively. We estimate this equation using non-linear least } \\
\text { squares. We adjust the point estimates and standard errors using } \\
\text { a multiple imputation procedure. }\end{array}$} \\
\hline
\end{tabular}

\begin{tabular}{lccc}
\hline \multicolumn{4}{c}{ Table 5. Congestion Equation } \\
\hline Variable & Coefficient & \multicolumn{1}{c}{ Std. Error } \\
\hline constant & -8.4146 & $(* * *)$ & 1.1556 \\
urban-lane-miles/adult & $-1.4160 \quad(* * *)$ & 0.1563 \\
vma+urban & $0.4600 \quad(* *)$ & 0.1078 \\
pop. density & $1.1647 \quad(* * *)$ & 0.0604 \\
percent trucks & $0.4636(* * *)$ & 0.2644 \\
\hline & & & \\
Observations & 1938 & \\
Adjusted $\mathrm{R}^{2}$ & 0.946 & \\
\hline
\end{tabular}

Notes: $(* * *),(* *)$ and $(*)$ indicate that the coefficient is statistically significant at the $1 \%, 5 \%$ and $10 \%$ level respectively. We estimate this equation using non-linear least squares. We adjust the point estimates and standard errors using a multiple imputation procedure. 


\begin{tabular}{|c|c|c|c|c|}
\hline \multirow[b]{2}{*}{ Elasticity } & \multicolumn{2}{|c|}{$\begin{array}{l}\text { Evaluated at 1966-2004 mean } \\
\text { levels of interacting variables }\end{array}$} & \multicolumn{2}{|c|}{$\begin{array}{l}\text { Evaluated at } 2004 \text { levels of } \\
\text { interacting variables }\end{array}$} \\
\hline & Short Run & Long Run & Short Run & Long Run \\
\hline \multicolumn{5}{|l|}{ Measures of induced demand } \\
\hline $\begin{array}{l}\text { VMT with respect to road-miles per state } \\
\text { land area }\end{array}$ & $\begin{array}{c}0.019 \\
(0.008)\end{array}$ & $\begin{array}{c}0.094 \\
(0.038)\end{array}$ & $\begin{array}{c}0.019 \\
(0.008)\end{array}$ & $\begin{array}{c}0.093 \\
(0.037)\end{array}$ \\
\hline $\begin{array}{l}\text { VMT with respect to urban lane mileage, } \\
\text { working through congestion }\end{array}$ & $\begin{array}{c}0.013 \\
(0.004)\end{array}$ & $\begin{array}{c}0.066 \\
(0.020)\end{array}$ & $\begin{array}{c}0.018 \\
(0.004)\end{array}$ & $\begin{array}{c}0.093 \\
(0.021)\end{array}$ \\
\hline $\begin{array}{l}\text { Total induced demand effect: } \\
\text { from expansion in total road mileage } \\
\text { from expansion in urban lane widths }\end{array}$ & $\begin{array}{l}0.032 \\
0.013\end{array}$ & $\begin{array}{l}0.160 \\
0.066\end{array}$ & $\begin{array}{l}0.037 \\
0.018\end{array}$ & $\begin{array}{l}0.186 \\
0.093\end{array}$ \\
\hline \multicolumn{5}{|l|}{ Other elasticities } \\
\hline Travel delay with respect to fuel efficiency & $\begin{array}{c}0.022 \\
(0.005)\end{array}$ & $\begin{array}{c}0.111 \\
(0.028)\end{array}$ & $\begin{array}{c}0.012 \\
(0.004)\end{array}$ & $\begin{array}{c}0.060 \\
(0.018)\end{array}$ \\
\hline Fuel consumption with respect to fuel price & $\begin{array}{l}-0.075 \\
(0.005)\end{array}$ & $\begin{array}{c}-0.361 \\
(0.029)\end{array}$ & $\begin{array}{l}-0.055 \\
(0.007)\end{array}$ & $\begin{array}{l}-0.285 \\
(0.038)\end{array}$ \\
\hline $\begin{array}{l}\text { VMT with respect to per-mile fuel cost: } \\
\text { using full model (Eq. } 3 \text { and } 4 \mathrm{a} \text { ) }\end{array}$ & $\begin{array}{l}-0.047 \\
(0.004)\end{array}$ & $\begin{array}{l}-0.241 \\
(0.023)\end{array}$ & $\begin{array}{l}-0.026 \\
(0.007)\end{array}$ & $\begin{array}{l}-0.131 \\
(0.034)\end{array}$ \\
\hline excluding congestion (Eq. 3 and 4b) & $\begin{array}{l}-0.048 \\
(0.004)\end{array}$ & $\begin{array}{r}-0.246 \\
(0.024) \\
\end{array}$ & $\begin{array}{l}-0.026 \\
(0.007) \\
\end{array}$ & $\begin{array}{l}-0.135 \\
(0.035) \\
\end{array}$ \\
\hline
\end{tabular}

Notes: Asymptotic standard errors are in parenthesis, computed using a Wald coefficient restriction test. 
Table 7. Measures of Induced Demand

\begin{tabular}{|c|c|c|c|c|}
\hline \multirow[t]{2}{*}{ Measure of Capacity } & \multirow[t]{2}{*}{$\begin{array}{c}\text { Price index for } \\
\text { deflating } \\
\text { income } \\
\end{array}$} & \multirow[t]{2}{*}{ Time Period } & \multicolumn{2}{|c|}{$\begin{array}{c}\text { Short-run elasticity of } \\
\text { VMT with respect to } \\
\text { capacity measure }\end{array}$} \\
\hline & & & Estimate & (Std Err) \\
\hline \multicolumn{5}{|l|}{ Single Equation Models - Noland Specification } \\
\hline 1. $\log ($ nonlocal lane miles per capita) & GDP deflator & 1984-1996 & 0.138 & $(0.029)$ \\
\hline 2. $\log ($ nonlocal lane miles per capita) & CPI & 1984-1996 & 0.086 & $(0.027)$ \\
\hline 3. $\log ($ nonlocal lane miles per adult) & CPI & 1984-1996 & 0.078 & $(0.026)$ \\
\hline 4. $\log$ (nonlocal lane miles per adult) & CPI & 1980-2004 & 0.036 & $(0.009)$ \\
\hline 5. $\log ($ nonlocal lane miles per adult) & CPI & 1966-2004 & 0.031 & $(0.004)$ \\
\hline \multicolumn{5}{|c|}{ Single Equation Model with Additional Exogenous Control Variables } \\
\hline 6. $\log$ (nonlocal lane miles per adult) & CPI & 1966-2004 & 0.012 & $(0.004)$ \\
\hline log(nonlocal lane miles per adult) & GDP deflator & 1966-2004 & 0.012 & $(0.004)$ \\
\hline \multicolumn{5}{|l|}{ Four Equation Model } \\
\hline 7. Two capacity measures: & CPI & 1966-2004 & & \\
\hline $\log ($ urban lane miles per adult) & & & 0.013 & $(0.004)$ \\
\hline log(road-miles per land area) & & & 0.019 & $(0.008)$ \\
\hline combined effect from expanding total road mileage & & & 0.032 & $(0.008)$ \\
\hline
\end{tabular}


Table 8. Four-Equation Model Sensitivity Analysis

\begin{tabular}{|c|c|c|c|c|}
\hline Dependent variable: log VMT per adult. & $1966-2004$ & 1966-2004 & 1966-2004 & 1984-2004 \\
\hline Independent variable: & Base Model & Omit Alaska & $\begin{array}{c}\text { Different road- } \\
\text { mileage } \\
\text { coefficient after } \\
1997\end{array}$ & No Imputation \\
\hline \multicolumn{5}{|l|}{ Induced demand variables } \\
\hline $\log$ (congestion) & $\begin{array}{c}-0.009 \\
(0.003)\end{array}$ & $\begin{array}{c}-0.008 \\
(0.002)\end{array}$ & $\begin{array}{c}-0.008 \\
(0.002)\end{array}$ & $\begin{array}{l}-0.007 \\
(0.003)\end{array}$ \\
\hline $\log$ (road-miles/land area) & $\begin{array}{c}0.019 \\
(0.008)\end{array}$ & $\begin{array}{c}0.015 \\
(0.007)\end{array}$ & $\begin{array}{c}0.019 \\
(0.007)\end{array}$ & $\begin{array}{c}0.024 \\
(0.008)\end{array}$ \\
\hline $\log ($ road-miles/land area)*post96 dummy & & & $\begin{array}{c}-0.001 \\
(0.001)\end{array}$ & \\
\hline \multicolumn{5}{|l|}{ Other control variables } \\
\hline $\log (\mathrm{VMT}$ per adult lagged) & $\begin{array}{c}0.795 \\
(0.013)\end{array}$ & $\begin{array}{c}0.810 \\
(0.012)\end{array}$ & $\begin{array}{c}0.800 \\
(0.012)\end{array}$ & $\begin{array}{c}0.708 \\
(0.017)\end{array}$ \\
\hline $\log$ (per adult income) & $\begin{array}{c}0.103 \\
(0.014)\end{array}$ & $\begin{array}{c}0.081 \\
(0.014)\end{array}$ & $\begin{array}{c}0.108 \\
(0.014)\end{array}$ & $\begin{array}{c}0.161 \\
(0.020)\end{array}$ \\
\hline $\log ($ cost of fuel) & $\begin{array}{l}-0.047 \\
(0.004)\end{array}$ & $\begin{array}{c}-0.042 \\
(0.004)\end{array}$ & $\begin{array}{l}-0.044 \\
(0.004)\end{array}$ & $\begin{array}{l}-0.049 \\
(0.006)\end{array}$ \\
\hline $\log ($ population per adult) & $\begin{array}{c}0.266 \\
(0.043)\end{array}$ & $\begin{array}{c}0.213 \\
(0.040)\end{array}$ & $\begin{array}{c}0.248 \\
(0.042)\end{array}$ & $\begin{array}{c}0.095 \\
(0.091)\end{array}$ \\
\hline degree of urbanization & $\begin{array}{l}-0.163 \\
(0.053)\end{array}$ & $\begin{array}{c}-0.100 \\
(0.050)\end{array}$ & $\begin{array}{l}-0.141 \\
(0.052)\end{array}$ & $\begin{array}{l}-0.058 \\
(0.083)\end{array}$ \\
\hline 19741979 dummy & $\begin{array}{c}-0.044 \\
(0.004)\end{array}$ & $\begin{array}{l}-0.042 \\
(0.004)\end{array}$ & $\begin{array}{l}-0.044 \\
(0.004)\end{array}$ & \\
\hline trend & $\begin{array}{c}0.0010 \\
(0.0003)\end{array}$ & $\begin{array}{c}0.0009 \\
(0.0003)\end{array}$ & $\begin{array}{c}0.0007 \\
(0.0003)\end{array}$ & $\begin{array}{c}0.0000 \\
(0.0004)\end{array}$ \\
\hline \multicolumn{5}{|l|}{ Endogenous variables } \\
\hline $\log ($ vehicle stock per adult) & $\begin{array}{c}0.034 \\
(0.010)\end{array}$ & $\begin{array}{c}0.031 \\
(0.009)\end{array}$ & $\begin{array}{c}0.033 \\
(0.009)\end{array}$ & $\begin{array}{c}0.030 \\
(0.010)\end{array}$ \\
\hline Fuel cost \& interactions & included & included & included & included \\
\hline Congestion interactions & included & included & included & included \\
\hline Autocorrelation parameter (rho) & -0.076 & -0.095 & -0.081 & -0.151 \\
\hline $\begin{array}{l}\text { Notes: We estimate these four specifications using nonl } \\
\text { fuel intensity. We also use the same set instruments fror } \\
\text { order autocorrelatede errors; Eviews } 5 \text { applies a standard } \\
\text { least squares (Quantitative Micro Software } 2004 \text {, eq } 17 \text {. } \\
\text { congestion measures back to 1966, repeating multiple ti }\end{array}$ & $\begin{array}{l}\text { ree-stage lea } \\
\text { sae model pr } \\
\text { rmation and } \\
\text { ot the specifi } \\
\text { compute me }\end{array}$ & $\begin{array}{l}\text { res to contro } \\
\text { in Table } 2 \text {. } \\
\text { tes the resul } \\
\text { with pre } 19 \\
\text { standard er }\end{array}$ & $\begin{array}{l}\text { he endogeneit } \\
\text { specifications } \\
\text { onlinear equati } \\
\text { a, we impute t } \\
\text { coefficient es }\end{array}$ & $\begin{array}{l}\text { rehicle stock and } \\
\text { control for first- } \\
\text { ing nonlinear } \\
\text { pacity and } \\
\text { es. }\end{array}$ \\
\hline
\end{tabular}




\section{Appendix A: Data sources}

Adult population

Definition: midyear population estimate, 18 years and over.

U.S. Census Bureau.

Corporate Average Fuel Economy Standard (Miles Per Gallon)

National Highway Traffic Safety Administration (NHTSA), CAFE

Automotive Fuel Economy Program, Annual update 2004, Table I-1.

Congestion (total hours of delay per adult)

1982 -2003: Texas Transportation Institute 2004 Urban Mobility Report.

Note: See text for a full description of how we generated the values for years 1966-1981 and 2004.

Consumer price index - all urban consumers

Bureau of Labor Statistics (BLS), CPI (1982-84=100).

Note: all monetary variables (gas tax, new passenger vehicle price index, price of gasoline, personal income) are put in real 1987 dollars by first deflating by this CPI and then multiplying by the CPI in year 1987. The purpose of using 1987 is for ease in replicating Haughton and Sarkar (1996).

Highway Use of Gasoline (millions of gallons per year)

1966-1995: FHWA, Highway Statistics Summary to 1995, Table MF-226.

1996-2004: FHWA, Highway Statistics, annual editions, Table MF-21.

Income per capita (\$/year, 1987 dollars)

Primary measure: Personal income divided by midyear population.

Personal income is from Bureau of Economic Analysis (BEA).

Interest rate: national average interest rate for auto loans (\%)

Definition: average of rates for new-car loans at auto finance companies and at commercial banks.

Source: Federal Reserve System, Economic Research and Data, Federal Reserve Statistical Release G.19 “Consumer Credit”. Available starting 1971for auto finance companies, 1972 for commercial banks. For earlier years in each series, we use the predicted values from a regression explaining that rate using a constant and Moody's AAA corporate bond interest rate, based on years 1971-2004 (finance companies) or 1972- 2004 (commercial banks).

New Car Price Index: price index for U.S. passenger vehicles, city average, not seasonally adjusted $(1987=100)$

Source: Bureau of Labor Statistics web site.

Note: Original index has 1982-84=100.

Number of vehicles: Number of automobiles and light trucks registered 1966-1995: FHWA, Highway Statistics Summary to 1995, Table MV-201. 1996-2004: FHWA, Highway Statistics, annual editions, Table MV-1 
Note: “Light trucks” include personal passenger vans, passenger minivans, utility-type vehicles, pickups, panel trucks, and delivery vans.

Price of gasoline (cents per gallon, 1987 dollars)

Data Set A: U.S. Department of Energy (USDOE 1977), Table B-1, pp. 93-94 (contains 1960-1977).

Data Set B: Energy Information Administration, State Energy Data 2000: Price and Expenditure Data, Table 5 (contains 1970-2000).

2001-2004: Energy Information Administration, Petroleum Marketing Annual, Table A1.

Note: We use Data Set B for 1970-2000, and for the earlier years we use predicted values

from a regression explaining Set B values for overlapping years (1970-1977) based on a

linear function of Set A values.

Public lane mileage: Total number of lane miles in state

1980-1995: FHWA, Highway Statistics Summary to 1995, Table HM-220.

1996-2004: FHWA, Highway Statistics, annual editions, Table HM-20.

Number of Licensed Drivers

1966-1995: FHWA, Highway Statistics Summary to 1995, Table DL-201. 1996-2004: FHWA, Highway Statistics, annual editions, Table DL-1C.

Notes: Some outliers in this series were replaced by values given by a fitted polynomial of degree 3.

Urban Lane Mileage (miles): Total municipal lane mileage

1980-1995: FHWA, Highway Statistics Summary to 1995, Table HM-220.

1996-2004: FHWA, Highway Statistics, annual editions, Table HM-20.

Urbanization: Share of total state population living in Metropolitan Statistical Areas (MSAs), with MSA boundaries based on December 2003 definitions.

Available starting 1969; for earlier years, extrapolated from 1969-79 values assuming constant annual percentage growth rate. Source: Bureau of Economic Analysis, Regional Economic Accounts

VMT (Vehicle Miles Traveled), in millions 1966-1979: FHWA, Highway Statistics, annual editions, Table VM-2.

1980-1995: FHWA, Highway Statistics Summary to 1995, Table VM-202.

1996-2004: FHWA, Highway Statistics, annual editions, Table VM-2. 


\section{Appendix B: Constructing the measure of congestion}

The Texas Transportation Institute (TTI) provides an annual measure of congestion for the 85 largest urbanized areas in the US. Their data, which come from the FHWA's Highway Performance Monitoring System database, begin in 1982. Please refer to the TTI’s technical documentation for more information on how they measured congestion. This section describes how we generated a statewide measure of congestion for years 1982-2004.

Since the model uses statewide data, we simply aggregated the urbanized area numbers by state for each year then divided by adult population to create annual travel delay per adult. However, in order to do this, we first had to adjust annual travel delay for the 14 urbanized areas that cross one or more state borders. There were two sources of data we used to do this apportioning.

First, the decennial census provides a breakdown of urbanized area population by state. The information for the 1990 and 2000 census was available online from the American FactFinder website. Similar data for the 1980 census is not online, but can be found in the Census report PC80-S1-14 "Population and Land Area of Urbanized Areas for the United States and Puerto Rico: 1980 and 1970".

Unfortunately, annual population estimates are not available for urbanized areas and only exist at the MSA level. For the most part, MSAs are very similar to urbanized areas but the population estimates are not exactly the same. The MSAs tend to encompass larger geographical regions than the urbanized areas, usually including more suburbs.

We ended up using the decennial census data (at the urbanized area level) to do the apportioning. In order to find the intercensal population ratios, we linearly interpolated the missing data in between years 1980 and 1990 and 1990 and 2000 and used the year 2000 ratio for 2001-2004. 


\section{Appendix C: Multiple imputation procedure}

1. We start with regressions ("imputation equations”) of each of the two imputed variables (total delay per adult, lane-miles per adult) on all of the $k$ exogenous variables in the fourequation system, for years 1982-2004 (for which full data are available). From each regression $i=1,2$, where $i$ indexes the imputed variable, we obtain a vector of estimated coefficients $B_{i}$ and an estimated variance-covariance matrix $W_{i}$.

2. Next we draw $M=20$ samples $B_{i}^{m}(m=1, \ldots, M)$ from the sampling distribution of the estimated coefficients, which is multivariate normal with mean $B_{i}$ and variance $W_{i}{ }^{20}$

3. For each draw $B_{i}^{m}$, we impute the missing data for years 1966-1981 using $B_{i}^{m}$ and the values of the exogenous variables in the imputation equations. We insert those imputed values into the rest of the data set and estimate the full simultaneous model as already described, obtaining estimated coefficient $\tilde{\beta}_{m}$ and variance-covariance matrix $\tilde{\Omega}_{m}$.

4. Finally, we compute our best point estimates $\hat{\beta}$ and $\hat{\Omega}$ of the parameter vector and its covariance matrix, as explained by Brownstone and Steimetz (2005):

$$
\begin{aligned}
& \hat{\beta}=\frac{1}{M} \sum_{j=1}^{M} \tilde{\beta}_{m} \\
& \hat{\Omega}=\frac{1}{M} \sum_{m=1}^{M} \tilde{\Omega}_{m}+\left(\frac{M+1}{M \cdot(M-1)}\right) \sum_{m=1}^{M}\left(\tilde{\beta}_{m}-\hat{\beta}\right)\left(\tilde{\beta}_{m}-\hat{\beta}\right)^{\prime} .
\end{aligned}
$$

Note that $\hat{\beta}$ is just the average of our simulated values $\tilde{\beta}_{m}$, while $\hat{\Omega}$ takes account of both the usual sampling errors in each of the vectors $\tilde{\beta}_{m}$, as estimated by the mean of matrices $\tilde{\Omega}_{m}$, and the simulation error in drawing only a finite number of those vectors, related to the squared deviations between $\tilde{\beta}_{m}$ and their average value.

\footnotetext{
${ }^{20}$ We obtain a single draw $B_{i}^{m}$ in the following manner. First, we write $W_{i}$ as $\Lambda_{i}^{\prime} \Lambda_{i}$ using the Cholesky decomposition, where $\Lambda_{i}$ is a lower triangular matrix. Next, we draw a vector of length $k$ from the standard univariate normal distribution, premultiply it by $\Lambda_{i}$, and add $B_{i}$.
} 


\section{Appendix D: Results of other estimated models}

The tables that follow provide more fully the results performed for Sections 5.2 and 5.3. 
Table D1. Single-Equation Models of Induced Demand

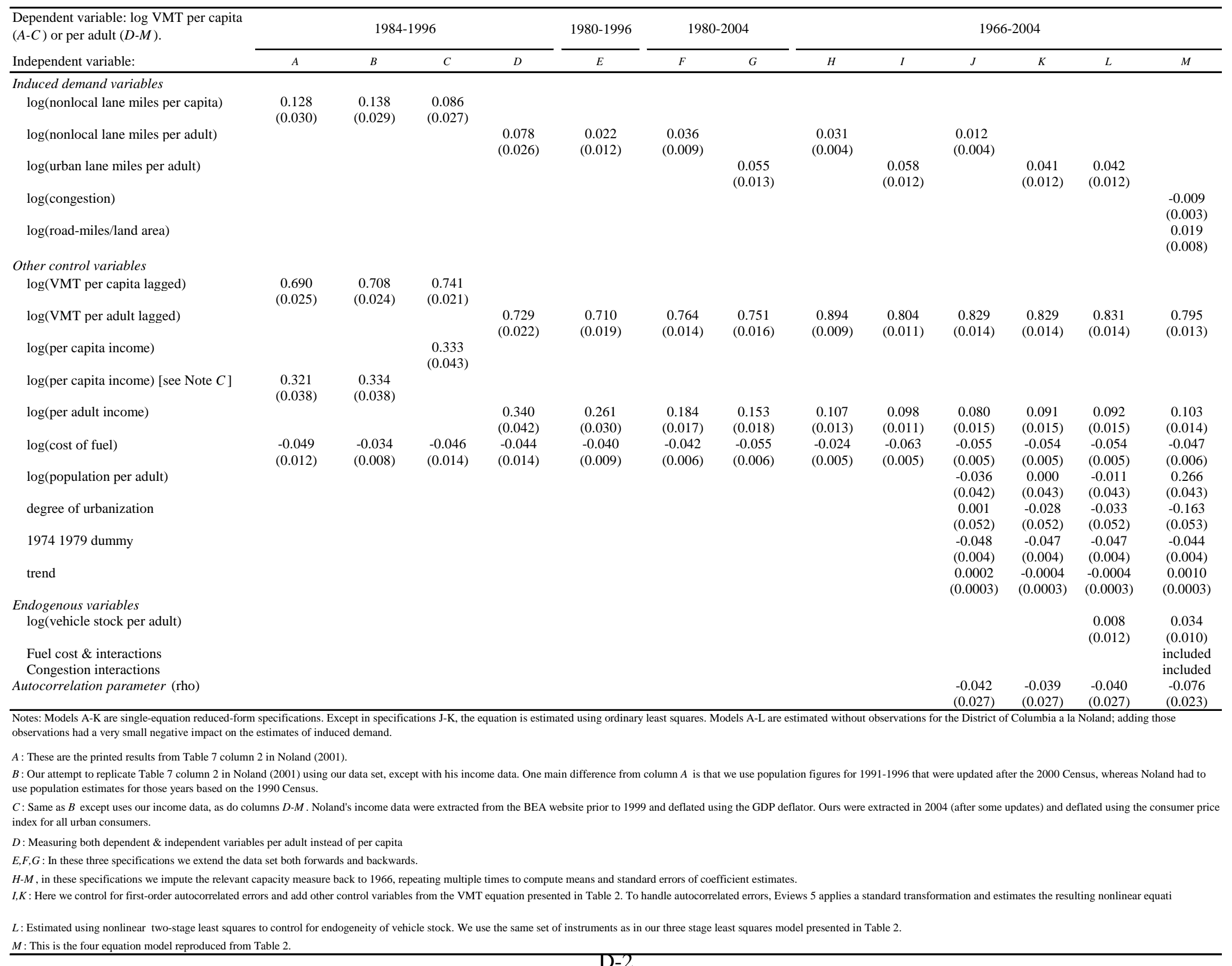


Sample: 1966-2004. Evaluated at 1984-2004 mean levels of interacting variables.
Sample: 1984-2004. Evaluated at 1984-2004 mean levels of interacting variables.

\begin{tabular}{|c|c|c|c|c|}
\hline \multirow[b]{2}{*}{ Elastic } & & \multirow{2}{*}{ Short Run } & \multirow{2}{*}{ Long Run } \\
\hline & Short Run & Long Run & & \\
\hline \multicolumn{5}{|l|}{ Measures of induced demand } \\
\hline $\begin{array}{l}\text { VMT with respect to road-miles per state } \\
\text { land area }\end{array}$ & $\begin{array}{c}0.019 \\
(0.007)\end{array}$ & $\begin{array}{c}0.094 \\
(0.038)\end{array}$ & $\begin{array}{c}0.023 \\
(0.011)\end{array}$ & $\begin{array}{c}0.082 \\
(0.036)\end{array}$ \\
\hline $\begin{array}{l}\text { VMT with respect to urban lane mileage, } \\
\text { working through congestion }\end{array}$ & $\begin{array}{c}0.013 \\
(0.002)\end{array}$ & $\begin{array}{c}0.065 \\
(0.012)\end{array}$ & $\begin{array}{c}0.009 \\
(0.002)\end{array}$ & $\begin{array}{c}0.033 \\
(0.014)\end{array}$ \\
\hline $\begin{array}{l}\text { Total induced demand effect: } \\
\text { from expansion in total road mileage }\end{array}$ & 0.031 & 0.159 & 0.033 & 0.114 \\
\hline \multicolumn{5}{|l|}{ Other elasticities } \\
\hline Travel delay with respect to fuel efficiency & $\begin{array}{c}0.013 \\
(0.004)\end{array}$ & $\begin{array}{c}0.066 \\
(0.019)\end{array}$ & $\begin{array}{c}0.051 \\
(0.015)\end{array}$ & $\begin{array}{c}0.170 \\
(0.047)\end{array}$ \\
\hline Fuel consumption with respect to fuel price & $\begin{array}{l}-0.057 \\
(0.007)\end{array}$ & $\begin{array}{l}-0.293 \\
(0.035)\end{array}$ & $\begin{array}{l}-0.054 \\
(0.012)\end{array}$ & $\begin{array}{l}-0.181 \\
(0.045)\end{array}$ \\
\hline $\begin{array}{l}\text { VMT with respect to per-mile fuel cost: } \\
\text { using full model (Eq. } 3 \text { and } 4 a \text { ) }\end{array}$ & $\begin{array}{l}-0.028 \\
(0.006)\end{array}$ & $\begin{array}{l}-0.143 \\
(0.033)\end{array}$ & $\begin{array}{l}-0.048 \\
(0.008)\end{array}$ & $\begin{array}{l}-0.159 \\
(0.029)\end{array}$ \\
\hline excluding congestion (Eq. 3 and 4b) & $\begin{array}{l}-0.028 \\
(0.006)\end{array}$ & $\begin{array}{l}-0.147 \\
(0.033)\end{array}$ & $\begin{array}{l}-0.048 \\
(0.008)\end{array}$ & $\begin{array}{l}-0.163 \\
(0.028)\end{array}$ \\
\hline
\end{tabular}

Notes: Asymptotic standard errors are in parenthesis, computed using a Wald coefficient restriction test. 


\section{Appendix E: Derivation of long-run elasticities}

For stage 1 of the procedure, we rewrite equations (9) with steady-state values for the endogenous variables, using the notation:

$$
m \equiv v m a_{t}=v m a_{t-1} ; \quad v \equiv v e h_{t}=v e h_{t-1} ; \quad c \equiv \operatorname{cong}_{t} ; \quad \log E \equiv-\text { fint }_{t}=- \text { fint }_{t-1} .
$$

Equations 9(a,b,d) can then be written as:

$$
\begin{aligned}
& \left(1-\alpha^{m}\right) m=\alpha^{m v} v+\beta_{1}^{m} \cdot(p m)+\alpha^{m c} c+\beta_{K 1}^{m} \cdot(\text { cap } 1)+\text { constants } \\
& \left(1-\alpha^{v}\right) v=\alpha^{v m} m+\beta_{2}^{v} \cdot(p m)+\text { constants } \\
& c=\alpha^{c m} m+\beta_{K 2}^{c} \cdot(\text { cap } 2)+\text { constants }
\end{aligned}
$$

where here "constants” means anything that does not depend on variables pm, cap1, or cap2. Substituting the second and third of these equations into the first and solving for $m$ yields the function $\tilde{m}(\cdot) \equiv v m a^{\sim}(\cdot)$ giving $m$ as a function of $p m$ and of exogenous variables:

$$
\tilde{m}=\frac{\left(\beta_{1}^{m}+\alpha^{m v} \overline{\beta_{2}^{v}}\right)(p m)+\beta_{K 1}^{m} \cdot(\operatorname{cap} 1)+\alpha^{m c} \beta_{K 2}^{c} \cdot(\operatorname{cap} 2)+\text { constants }}{D^{L}}
$$

where definitions (15) apply. Long-run elasticities (14) are obtained simply by differentiating equation (E2).

Stage 2 involves solving the simultaneous system consisting of equations (E2) and (9c) for the two endogenous variables, $m$ and $\log E \equiv-$ fint. Substituting (E2) into (9c), we obtain

$$
\left(1-\alpha^{f}\right) \log E=-\alpha^{f m} \tilde{m}(\cdot)-\beta_{1}^{f} \cdot(p f)+\text { constants }
$$

where $\tilde{m}(\cdot)$ depends on $\log E$ and "constants" here indicates terms that do not depend on $p f$. Differentiating (E3) with respect to $p f$ and solving for $\partial(\log E) / \partial(p f)$ yields (16). Equation (17a) is obtained by applying chain rule for differentiating with respect to $\mathrm{pm}$ :

$$
\frac{\partial m^{*}(p f)}{\partial(p f)}=\frac{\partial \tilde{m}(p m)}{\partial(p m)} \cdot \frac{\partial(p f-\log E)}{\partial(p f)}=\varepsilon_{\tilde{M}, P M}^{L} \cdot\left(1-\varepsilon_{E^{*}, P F}^{L}\right)
$$

Equation (17b) is obtained by noting that the logarithm of steady-state fuel consumption is simply $m-\log E$. 